\title{
Competency of Rhizobial Inoculation in Sustainable Agricultural Production and Biocontrol of Plant Diseases
}

OPEN ACCESS

Edited by:

Everlon Cid Rigobelo,

São Paulo State University, Brazil

Reviewed by:

Maura Santos Reis De Andrade Da

Silva,

Universidade Estadual de São

Paulo, Brazil

Ajar Nath Yadav,

Eternal University, India

John M. Maingi,

Kenyatta University, Kenya

*Correspondence:

Erana Kebede

eranak.neda@gmail.com

erana.kebede@haramaya.edu.et orcid.org/0000-0002-3584-6757

Specialty section:

This article was submitted to Crop Biology and Sustainability,

a section of the journal

Frontiers in Sustainable Food Systems

Received: 20 June 2021

Accepted: 29 July 2021

Published: 27 August 2021

Citation:

Kebede E (2021) Competency of Rhizobial Inoculation in Sustainable Agricultural Production and Biocontrol of Plant Diseases.

Front. Sustain. Food Syst. 5:728014. doi: 10.3389/fsufs.2021.728014

\section{Erana Kebede* \\ School of Plant Sciences, College of Agriculture and Environmental Sciences, Haramaya University, Dire Dawa, Ethiopia}

The rate of growth of the global population poses a risk to food security, demanding an increase in food production. Much of the world's cultivable soils also do not have ideal farming conditions such as soil health and fertility problem and increased pest attacks, which are challenges of food production. In this perspective, there is a need to increase agricultural production using a more economically and environmentally sustainable approach. As practices of agricultural production and improvement, rhizobial inoculants represent a practically effective, ecologically safe, and economically alternative means of realizing maximum agricultural production. This review addressed how rhizobial inoculation advances agricultural production through improving plant growth, nutrient availability and uptake, and yields by enhancing bio-fixation of atmospheric nitrogen and solubilization of soil nutrients. Besides, rhizobial inoculants offer biocontrol of plant diseases by providing resistance against disease-causing pathogens or suppression of diseases. Mechanisms involved in biocontrol of plant diseases include competition for infection sites and nutrients, activation of induced systemic resistance, and production of substances such as growth hormones, antibiotics, enzymes, siderophores, hydrogen cyanide, and exo-polysaccharides. Consequently, this approach is promising as sustainable agricultural practices have yet to supplement or replace chemical fertilizers, serving as a basis for future research on sustainable agricultural production. Despite the multifunctional benefits of rhizobial inoculation, there is a variation in the implementation of this practice by farmers. Therefore, researchers should work on eradicating farmers' constraints in using rhizobia, and future studies should be concentrated toward the methods of improving inoculant quality and promotion of the technology.

Keywords: biocontrol, inoculation, nitrogen fixation, nutrient uptake, rhizobia

\section{INTRODUCTION}

The growth rate of the global human population increases alarmingly, demanding a substantial increase in food production. This increase in demand for food needs to be fulfilled using the current arable land, which is currently under stress from an increasing human population, harsh climatic conditions, degradation in soil fertility and health, and emerging and re-emerging diseases (Koskey et al., 2021). In this context, harnessing agricultural resources such as legumes and legume-incorporating production approaches can play an imperative role by providing 
manifold services harmonized with sustainability issues (Stagnari et al., 2017; Kebede, 2020a). Legumes play a crucial role in the traditional diets of many regions throughout the world and provide a multitude of benefits to both the soil and other crops grown in mixture with them and following them in cropping systems. They contribute a major way toward poverty reduction, by improving food security, nutrition, and health, and sustaining the natural resource base (Kebede, 2020a,b). Legumes also play a pivotal role in nutrient enrichment and cycling in agricultural production systems. Predominantly, the exceptional capacity of legumes to fix atmospheric nitrogen through symbiotic association with rhizobia, a root nodule bacteria that comprise Rhizobium, Bradyrhizobium, Sinorhizobium, Azorhizobium, and Mesorhizobium, could be used to increase agricultural productivity (Kebede, 2020a; Kebede et al., 2021). However, the success of this symbiotic association is dependent on the capability of legumes to form effective nitrogen-fixing symbioses with rhizobia. Many agricultural soils, however, do not have an adequate amount of rhizobia in terms of number, quality, and effectiveness to form effective nitrogen fixation and, hence, boost production (Zahran, 1999). These circumstances necessitate the introduction of inoculants and manipulation of the legume rhizosphere by inoculation to permit effective nodulation and nitrogen fixation and subsequent increase in agricultural productivity (Abbasi et al., 2010; Wolde-meskel et al., 2018; Matse et al., 2020; Yadav et al., 2021).

On the other hand, modern agriculture is facing critical challenges in which chemical fertilizers are utilized to attain higher crop yield while enhancing negative ecological impacts (Tariq et al., 2020; Koskey et al., 2021; Yadav et al., 2021). Hence, the uses of inoculants are key approaches along with their recognized achievements of crop yield improvement and biocontrol of plant diseases (Yadav et al., 2021). As practices of agricultural production and improvement, the utilization of rhizobial inoculants in legumes has been recognized for a very long time (Abdullahi et al., 2013). As a result, inoculation of legumes with rhizobia remains an effective and suitable means of presenting efficient rhizobia to legume rhizospheres and soils (Deaker et al., 2006). This is vital for increasing crop yield in farmlands, especially where the supply of nitrogen fertilizers restricts crop production and productivity. The practice increases the infection establishment, nodulation, biomass, yield component, yield, and nutrient uptake of the legume crops. The use of rhizobia as an inoculant and legumeincorporating production systems are, thus, an imperative practice in sustainable agricultural production, which can be a cost-effective substitute to and/or supportive way out of chemical fertilizers in agriculture. Furthermore, the practice can result in a good benefit-cost ratio as the price of inoculant is only about $1 \%$ of the total cost of agricultural inputs (Lindeque, 2007).

Rhizobial inoculation, at large, improves soil health and productivity and crop productivity in sustainable organic farming and embraces a great promise to improve agricultural productivity through ecologically sustainable and improved nutrient supplies and uses. Numerous studies have affirmed that the use of rhizobia as an inoculant can increase the efficiency of the symbiotic processes and can profoundly boost the growth, development, and yield of crops by various mechanisms of actions under flexible conditions (Uddin et al., 2014; Singh and Singh, 2018; Wolde-meskel et al., 2018; Matse et al., 2020). Therefore, rhizobial inoculants can be used to resolve soil fertility problems and reduce the use of synthetic nitrogen fertilizers with a subsequent decrease of ecological contamination (Woldemeskel et al., 2018).

The use of rhizobial inoculants as biocontrol agents against plant diseases has also been practiced for centuries as reports confirmed that rhizobial inoculants provide plant resistance against disease-causing pathogens (Ahemad and Kibret, 2014; Gopalakrishnan et al., 2015; Khan et al., 2017; Volpiano et al., 2019). Numerous mechanisms can be employed by rhizobia for biocontrol and suppression of diseases, which include competition for infection sites and resources, activation of induced systemic resistance (ISR), and production of growth hormones, antibiotics, enzymes, siderophores, and hydrogen cyanide (HCN) (Deshwal et al., 2003; Ahemad and Kibret, 2014; Tariq et al., 2020).

The use of rhizobial inoculants can be, thus, emphasized as one of the best approaches for sustainable agricultural production and a feasible solution to sustain the twin problems of global food security and environmental stability (Tariq et al., 2020; Yadav et al., 2021). This approach is important, particularly in the developing world where much of the increases in food production come from the need to feed an alarmingly increasing population (Koskey et al., 2021). As a result, the documentation of available information on the potential of rhizobia in improving crop productivity and providing resistance against plant diseases will be beneficial for the endorsement of this approach and the development of sustainable agricultural systems. The generation of wide-ranging knowledge on this approach can also be a current need to enhance the adoption, exploitation, and successes of this approach. Besides, the utilization of this approach in mitigating the effects of various constraints makes it a novel, cheap, and advanced technology which can stimulate research and commercial interests related to this approach. Hence, this paper explores the need and competency of sustainable and environmentally friendly rhizobial inoculation approaches in agricultural systems, especially in improving crop productivity, biocontrol of plant diseases along with their mechanisms of action, and associated benefits in the agricultural system.

\section{RHIZOBIAL INOCULATION IN LEGUMES AND AGRICULTURAL SYSTEM Rhizobia Used as an Inoculant in Agriculture}

Intensive research attempts are proceeding to alleviate the effects of climate change and improve soil fertility and disease resistance of plants using organic agricultural approaches, comprising microbial inoculants. This is mainly because microbial inoculants are beneficial to mankind and can be used in the field of agriculture. The most antique microbe used as inoculants is "rhizobia," bacteria that are able to colonize the rhizosphere and establish a symbiotic association with legumes, which are used 
as a plant growth promoter and protector through biological nitrogen fixation, mobilization and solubilization of nutrients, production of siderophores, and discharge of phytohormones (Brockwell and Bottomley, 1995; Makoi et al., 2013; Koskey et al., 2021; Yadav et al., 2021). Particularly, research on inoculants and inoculation with rhizobia and legumes raised pronounced interest from researchers and companies in the 1970s (Santos et al., 2019). The practice of using rhizobial inoculants as bioinoculants and/or bio-pesticides signifies a potential promise for improving plant health and soil productivity and controlling and/or suppressing plant diseases (Deaker et al., 2006; Khan et al., 2017; Wolde-meskel et al., 2018; Volpiano et al., 2019; Matse et al., 2020). Consequently, this is part of an environmentally friendly approach for sustainable nutrient management and can be supplements or alternatives to chemical fertilizers.

Rhizobial inoculants usually contain live or dormant cells and are developed as carrier-based inoculants comprising effective microbes, and their formulation with different carrier materials allows long-term storage and higher efficacy (Ahemad and Kibret, 2014; Gopalakrishnan et al., 2015; Matse et al., 2020; Yadav et al., 2021). Following the inoculation, the organisms in the inoculants colonize plant roots, stimulate root growth, make nutrients available to the plants, and protect plants from various diseases. Hence, legume inoculation with rhizobia is a way of assuring that the strain of rhizobia appropriate for the legume cultivar being grown exists in the soil at the proper period and in numbers adequate to make a rapid and effective infection and succeeding nitrogen fixation (Zahran, 1999). The inventive objective of this practice is to stimulate biological nitrogen fixation to offer nitrogenous nutrients to a particular legume and other crops. The return of this practice is an increment in plant growth, nutrient uptake, yield, seed protein, and other traits and a reduction in the use of chemical fertilizers with the subsequent decrease of ecological contamination (Wolde-meskel et al., 2018).

Different studies have confirmed that rhizobial inoculation in legumes is recognized for stimulating growth and is an alternative to the expensive inorganic nitrogen fertilizers (Ndakidemi et al., 2006; Abbasi et al., 2010). Therefore, the use of appropriate inoculants in legumes offers an opportunity for improving productivity of legumes and other crops grown in integrated cropping systems such as crop rotation, intercropping, alley cropping, and green manuring. As a result, the phenomenon of rhizobial inoculation has gotten consideration due to its increasing contribution to agricultural productivity. The overview of the benefits of rhizobial inoculation, the nitrogenfixing process due to the application of rhizobia, and mechanisms of biological nitrogen fixation in legumes are described in Figure 1 .

Commercial rhizobial inoculants can be supplied to farmers in different forms such as solid, liquid, and freeze-dried formulations (Brockwell and Bottomley, 1995). Rhizobial inoculants need to be competitive and superior to the native rhizobial populations for nodule residence and effectiveness in fixing nitrogen. Therefore, rhizobial inoculants should be chosen for specific host legumes and ecological conditions (Stephens and Rask, 2000). An additional essential trait that needs to be considered is the persistence of the inoculants in the soils over the period (Zahran, 1999). At the recommended rates of inoculation, a suitable inoculant often dominates in nodulation, nitrogen fixation, and aftermath provision of the fixed nitrogen to crops (Brockwell and Bottomley, 1995). A study by Lindström et al. (1990) revealed that rhizobial inoculants can prevail in nodules for 5-15 years after their first inoculation into the soil. This confirms that rhizobial inoculants are competitive and effective saprophytes and reside in the soil for several years even in the non-existence of their legume host.

Several studies have shown that inoculation of legumes with rhizobia can improve the growth and development of plants through other mechanisms in addition to the provision of fixed nitrogen to plants (Chernin and Glick, 2012; Namvar et al., 2013; Tagore et al., 2013; Uddin et al., 2014; Singh and Singh, 2018; Wolde-meskel et al., 2018; Matse et al., 2020). Duan et al. (2009) reported that the presence of amino cyclopropane carboxylate (ACC) deaminase activity in some strains of rhizobia stimulates plant growth by reducing the levels of ethylene in the plants. Das et al. (2017) stated that legume seed inoculation with effective rhizobia leads to stimulation and accumulation of phenolic compounds, like isoflavonoid phytoalexins, and triggering of enzymes such as L-phenylalanine ammonia-lyase (PAL), chalcone synthase (CHS), peroxidase (POX), and polyphenol oxidase (PPO), which are involved in phenylpropanoid and isoflavonoid pathways, a rich source of metabolites in plants. Avis et al. (2008) reported that rhizobia help to solubilize phosphorus by producing low-molecular-weight organic acids that perform on inorganic phosphorus and can also promote improved resistance against plant pathogens.

Rhizobia consist of a diverse range of genera in the Alphaproteobacterial and Betaproteobacterial classes and are termed "Alpha-rhizobia" and "Beta-rhizobia," respectively (Sprent et al., 2017). The Alphaproteobacteria contains about 20 families; however, there are currently 13 genera of Alphaproteobacteria comprising legume-nodulating species, viz., Aminobacter, Azorhizobium, Bradyrhizobium, Devosia, Ensifer (Sinorhizobium), Mesorhizobium, Methylobacterium, Microvirga, Neorhizobium, Ochrobactrum, Phyllobacterium, Rhizobium, and Shinella. On the other hand, the Betaproteobacteria contains about 12 families of bacteria although there are currently two nodulating genera of Betaproteobacteria, viz., Burkholderia and Cupriavidus (Howieson and Dilworth, 2016). Presently, the number of correctly described species of legume-nodulating rhizobia is increasing at a rate of more than 10 species per year; however, rhizobial strains in only five genera of rhizobia are currently used as inoculants in agriculture (Table 1).

Almost all plants nodulated by rhizobial species in the genus indicated in Table $\mathbf{1}$ are in the family Leguminosae, which includes more than 700 genera and about 20,000 species, which are in turn classified into three subfamilies (Caesalpinioideae, Mimosoideae, and Papilionoideae), although the legume taxonomy is currently under revision (Sprent et al., 2017). Similarly, the taxonomy of rhizobia nodulating different legumes is also huge, and the wide-ranging lists of valid rhizobial species are continually updating. Rhizobial taxonomy is nowadays based on divergence chromosomal genes such as ribosomal RNA, and 


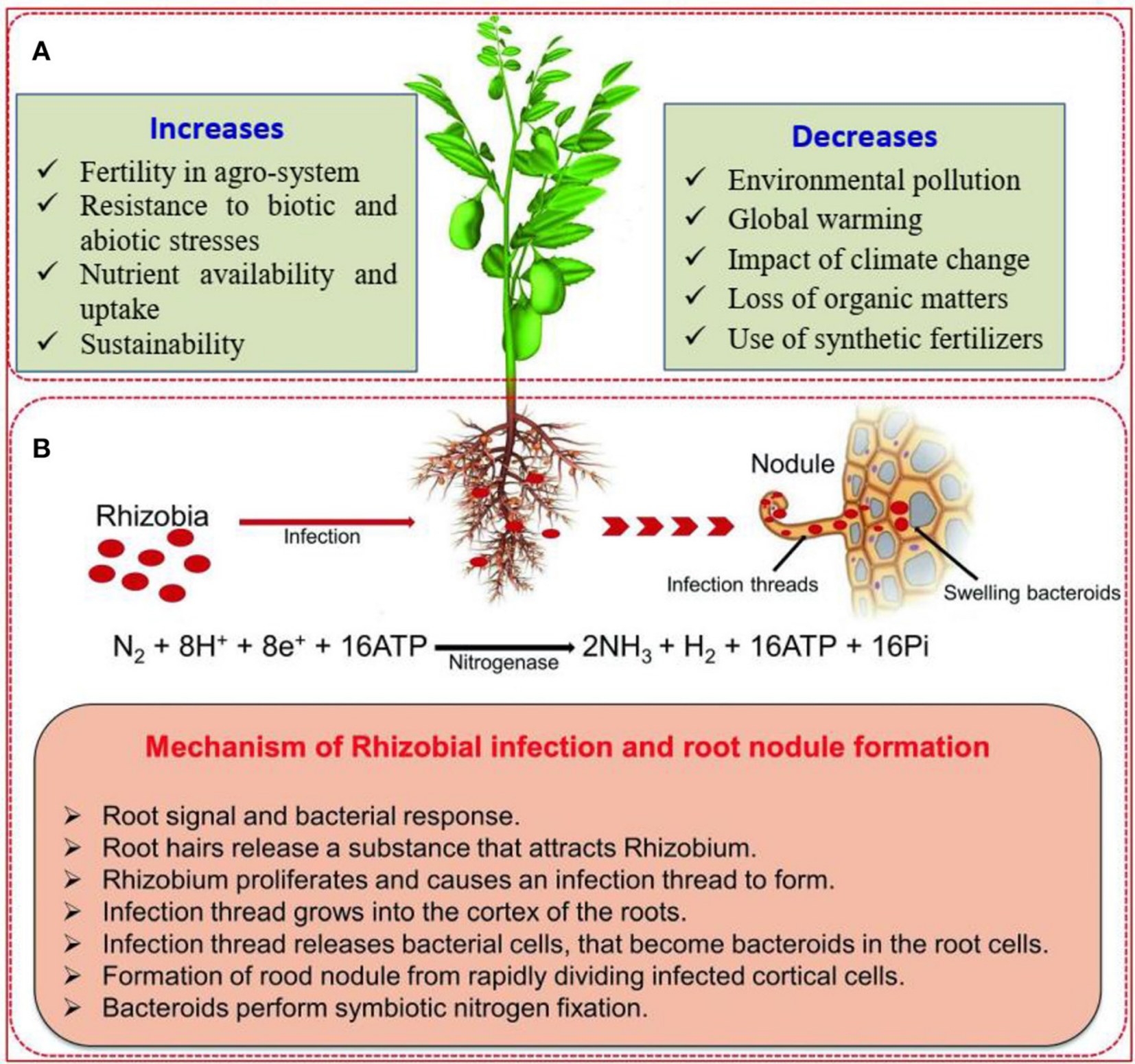

FIGURE 1 | (A) Overview of the benefits of biological nitrogen fixation by legumes in agricultural production. (B) Diagrammatic scheme showing the application of rhizobia and mechanisms of symbiotic nitrogen fixation in legumes. Source: Raza et al. (2020).

the genetics of symbiotic host specificity allowed variation of host range among rhizobial species (Shamseldin et al., 2017; Sprent et al., 2017). These indicate that there are relationships between rhizobial taxonomic groups (genera and species). A phylogeny of the currently confirmed symbiotic genera and species of Alpha- and Beta-rhizobia and their relationships are shown in Figure 2.

\section{Rhizobial Inoculation Improves the Growth, Yield Components, and Yields of Legumes}

In the field of sustainable agriculture, rhizobial inoculation has the competency to promote plant growth and stress resistance, recycle nutrients, improve soil fertility, and rectify soil contamination. These microorganisms have been used for improving plant productivity by directly contributing biologically fixed nitrogen, nutrient solubilization, and phytohormone production. At present, the use of these inoculants, especially in legume crops, is considered as a strategic component of the agricultural system as they improve the productivity of the crops sustainably without causing harm to the environment (Yadav et al., 2021). Reports from different authors have revealed that legume inoculation with rhizobia subsequently increased the nodulation, growth, and yields of legume crops. As stated by Herridge (2008), rhizobial 
TABLE 1 | Families, genera, and species of root nodule rhizobia and their host plant(s) or source(s).

\begin{tabular}{|c|c|c|c|}
\hline Family & Genus & Number of described species & Host plant(s) or source(s) \\
\hline \multicolumn{4}{|c|}{ Alphaproteobacteria } \\
\hline \multirow[t]{37}{*}{ Bradyrhizobiaceae } & Bradyrhizobium* & Bradyrhizobium japonicum & Glycine max \\
\hline & & Bradyrhizobium elkanii & Vigna unguiculata \\
\hline & & Bradyrhizobium liaoningensis & Glycine max \\
\hline & & Bradyrhizobium yuanmingense & Lespedeza spp. \\
\hline & & Bradyrhizobium betae & Beta vulgaris \\
\hline & & Bradyrhizobium canariense & Endemic genistoid \\
\hline & & Bradyrhizobium denitrificans & Not mentioned \\
\hline & & Bradyrhizobium iriomotense & Entada koshunensis \\
\hline & & Bradyrhizobium jicamae & Pachyrhizus erosus \\
\hline & & Bradyrhizobium pachyrhizi & \\
\hline & & Bradyrhizobium lablabi & Lablab purpureus and Arachis hypogaea \\
\hline & & Bradyrhizobium cytisi & Cytisus villosus \\
\hline & & Bradyrhizobium huanghuaihaiens & Glycine max \\
\hline & & Bradyrhizobium rifense & Cytisus villosus \\
\hline & & Bradyrhizobium daqingense & Glycine max \\
\hline & & Bradyrhizobium arachidis & Arachis hypogaea \\
\hline & & Bradyrhizobium retamae & Retama sphaerocarpa and Retama monosperma \\
\hline & & Bradyrhizobium diazoefficiens & Soybean \\
\hline & & Bradyrhizobium oligotrophicum comb. & Aeschynomene indica \\
\hline & & Bradyrhizobium ganzhouense & Acacia melanoxylon \\
\hline & & Bradyrhizobium ingae & Inga laurina \\
\hline & & Bradyrhizobium valentinum & Lupin \\
\hline & & Bradyrhizobium paxllaeri & Phaseolus lunatus L. \\
\hline & & Bradyrhizobium icense & \\
\hline & & Bradyrhizobium manausense & Cowpea \\
\hline & & Bradyrhizobium ottawaense & Soybean \\
\hline & & Bradyrhizobium neotropicale & Centrolobium paraense \\
\hline & & Bradyrhizobium erythrophlei & Erythrophleum fordii \\
\hline & & Bradyrhizobium ferriligni & \\
\hline & & Bradyrhizobium subterraneum & Arachis hypogaea \\
\hline & & Bradyrhizobium guangdongense & Peanut \\
\hline & & Bradyrhizobium guangxiense & \\
\hline & & Bradyrhizobium tropiciagri & Neonotonia wightii \\
\hline & & Bradyrhizobium embrapense & Desmodium heterocarpon \\
\hline & & Bradyrhizobium lupini comb & Lupinus \\
\hline & & Bradyrhizobium kavagense & Traditional Namibian pulses \\
\hline & & Bradyrhizobium vignae & Vigna and Arachis \\
\hline \multirow[t]{13}{*}{ Rhizobiaceae } & Rhizobium* & Rhizobium leguminosarum & Different host \\
\hline & & Rhizobium trifolii & Clover \\
\hline & & Rhizobium lupine & Lupine \\
\hline & & Rhizobium japonicum & Soybean \\
\hline & & Rhizobium loti & Lotus corniculatus \\
\hline & & Rhizobium fredii & Glycine max \\
\hline & & Rhizobium galegae & Galega orientalis \\
\hline & & Rhizobium leguminosarum bv. phaseoli & Phaseolus vulgaris \\
\hline & & Rhizobium tropici & Phaseolus vulgaris \\
\hline & & Rhizobium huakuii & Astragalus sinicus \\
\hline & & Rhizobium etli & Phaseolus vulgaris \\
\hline & & Rhizobium ciceri & Chickpea \\
\hline & & Rhizobium tianshanense & From saline desert soil \\
\hline
\end{tabular}


TABLE 1 | Continued

\begin{tabular}{|c|c|c|c|}
\hline Family & Genus & Number of described species & Host plant(s) or source(s) \\
\hline & & Rhizobium mediterrraneum & Chickpea \\
\hline & & Rhizobium gallicum & Phaseolus vulgaris \\
\hline & & Rhizobium giardinii & \\
\hline & & Rhizobium hainanense & Tropical legumes \\
\hline & & Rhizobium huautlense & Sesbania herbacea \\
\hline & & Rhizobium mongolense & Medicago ruthenica \\
\hline & & Rhizobium etli bv. mimosa & Mimosa affinis \\
\hline & & Rhizobium indigoferae & Indigofera spp. \\
\hline & & Rhizobium sullae & Hedysarum coronarium \\
\hline & & Rhizobium meliloti & \\
\hline & & Rhizobium loessense & Astragalus lespedeza \\
\hline & & Rhizobium daejeonense & Form nodules on Medicago sativa \\
\hline & & Rhizobium Iusitanum & Phaseolus vulgaris \\
\hline & & Rhizobium cellulosilyticum & Populus alba \\
\hline & & Rhizobium fabae & Vicia faba \\
\hline & & Rhizobium miluonense & Lespedeza \\
\hline & & Rhizobium multihospitium & Multiple legumes \\
\hline & & Rhizobium oryzae & Oryza alta and nodulate Phaseolus vulgaris and Glycine max \\
\hline & & Rhizobium pisi & Clover but can nodulate bea \\
\hline & & Rhizobium mesosinicum & Albizia, Kummerowia, and Dalbergia \\
\hline & & Rhizobium alamii & Legumes and non-legumes \\
\hline & & Rhizobium alkalisoli & Caragana intermedia \\
\hline & & Rhizobium tibeticum & Trigonella archiducis-nicolai \\
\hline & & Rhizobium herbae & Wild legumes in China \\
\hline & & Rhizobium sphaerophysae & Sphaerophysa salsula \\
\hline & & Rhizobium tubonense & Oxytropis glabra \\
\hline & & Rhizobium vallis & Phaseolus vulgaris and Mimosa pudica \\
\hline & & Rhizobium vignae & Mung bean, Vigna radiata \\
\hline & & Rhizobium halophytocola & Rosa rugosa \\
\hline & & Rhizobium leucaenae & Leucaena leucocephala \\
\hline & & Rhizobium grahamii & Dalea leporina, Leucaena leucocephala, and Clitoria ternatea \\
\hline & & Rhizobium mesoamericanum & Phaseolus vulgaris, siratro, cowpea, and Mimosa pudica \\
\hline & & Rhizobium helanshanense & Sphaerophysa salsula \\
\hline & & Rhizobium cauense & Herbaceous legume \\
\hline & & Rhizobium taibaishanense & Kummerowia striata \\
\hline & & Rhizobium paknamense & Lemna aequinoctialis \\
\hline & & Rhizobium calliandrae & Calliandra grandiflora \\
\hline & & Rhizobium mayense & \\
\hline & & Rhizobium jaguaris & \\
\hline & & Rhizobium qilianshanense & Oxytropis ochrocephala \\
\hline & & Rhizobium freirei & Phaseolus vulgaris \\
\hline & & Rhizobium pongamiae & Pongamia pinnata \\
\hline & & Rhizobium azibense & Phaseolus vulgaris \\
\hline & & Rhizobium laguerreae & Vicia faba \\
\hline & & Rhizobium pakistanensis & Arachis hypogaea \\
\hline & & Rhizobium paranaense & Phaseolus vulgaris \\
\hline & & Rhizobium bangladeshense & Lentil \\
\hline & & Rhizobium binae & \\
\hline & & Rhizobium lentis & \\
\hline & & Rhizobium puerariae & Pueraria candollei \\
\hline & & Rhizobium acidisoli & Phaseolus vulgaris \\
\hline
\end{tabular}


TABLE 1 | Continued

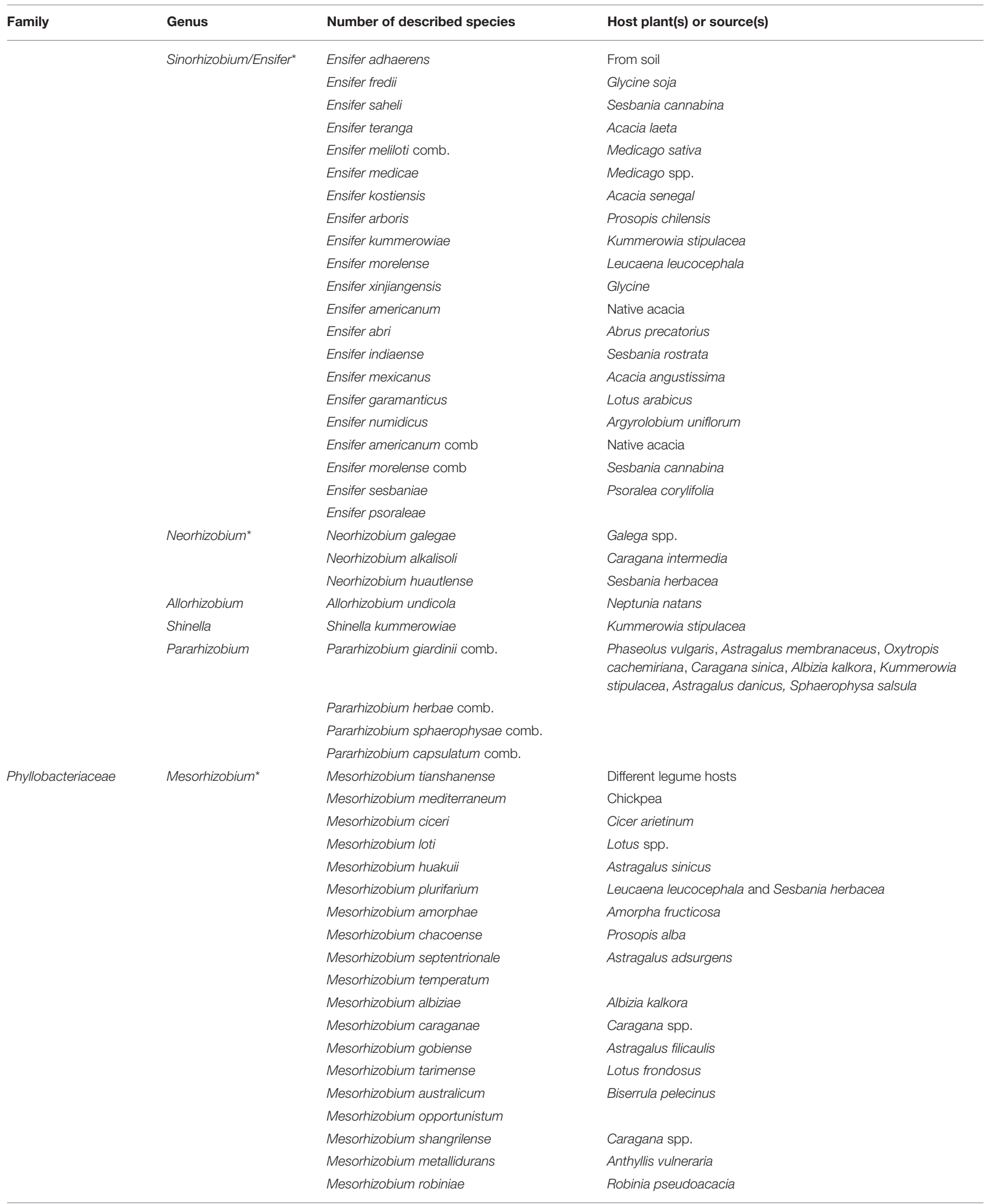


TABLE 1 | Continued

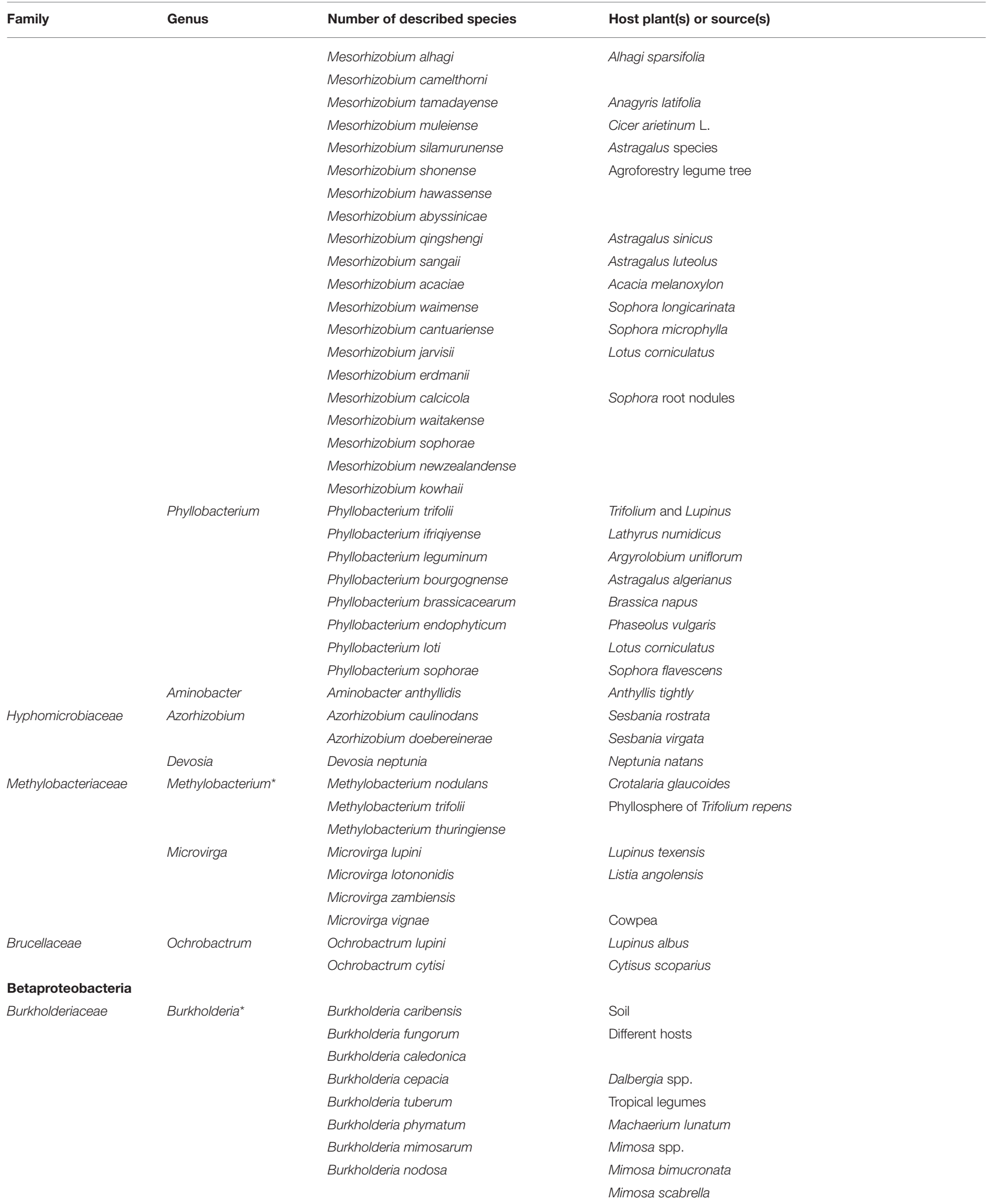


TABLE 1 | Continued

\begin{tabular}{lll}
\hline Family & Numus & Host plant(s) or source(s) \\
\hline & Burkholderia sabiae & Mimosa caesalpiniaefolia \\
& Burkholderia contaminans & Different hosts \\
& Burkholderia lata & \\
Burkholderia symbiotica & Mimosa spp. \\
& Burkholderia diazotrophica & Mimosa spp. \\
& Burkholderia sprentiae & Lebeckia ambigua \\
& Burkholderia dilworthii & \\
& Burkholderia aspalathi & Aspalathus abietina \\
& Burkholderia kirstenboschensis & Papilionoid legumes \\
Cupriavidus & Mimosa spp. \\
& Cupriavidus necator & Phaseolus vulgaris \\
& & Leucaena leucocephala \\
\hline
\end{tabular}

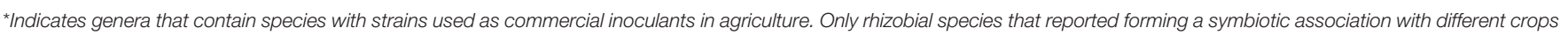
are mentioned in the above table. Source: Howieson and Dilworth (2016), Soenens and Imperial (2018), and Shamseldin et al. (2017).

inoculation is a method of insurance where a farmer, by paying a minor premium charge of inoculation, is protected against the possibility of nitrogen-deficient crops, which helps to overcome the reduction in crop yield and income. Among the growth and symbiotic parameters of legumes, the number of nodules and dry weight of root nodules can be an index for the degree of infection of the inoculated rhizobial species, resulting in nodule development, nodulation, and improvement of plant growth (Singh and Singh, 2018).

The positive results of inoculating legumes with rhizobia on the number of nodules and nodule dry weight per plant in different legumes were documented well (Ndakidemi et al., 2006; Singh and Singh, 2018; Wolde-meskel et al., 2018; Matse et al., 2020). Kumaga and Ofori (2004) reported an increment in nodulation and plant growth after inoculation of soybean varieties, both promiscuous and non-promiscuous, which can be attributed to the highly competitive capability of the rhizobial inoculant used. Likewise, Dey et al. (2004) showed that nodulation and plant growth were increased in peanuts following the inoculation of seeds with a diversity of rhizobial species. Huang and Erickson (2007) inoculated pea and lentil seeds with Rhizobium leguminosarum and stated that nodulation and shoot and root growth of both plants increased as a result of rhizobial inoculation. Similarly, the inoculation of lentil with Rhizobium leguminosarum enhanced seedling height, nodule number, and shoot biomass of the crop.

The increment in grain yields of various legumes because of rhizobial inoculation which also resulted in soil fertility improvements has been revealed by different authors (Tagore et al., 2013; Wolde-meskel et al., 2018). In Brazil, inoculation improved soybean grain yields by up to $750 \mathrm{~kg} / \mathrm{ha}$ (Coutinho et al., 1999). Nyoki and Ndakidemi (2013) inoculated cowpea with Bradyrhizobium japonicum in Tanzania and described that inoculation improved the number of pods per plant by $13.7 \%$, the number of seeds per pod by $11.6 \%$, the mean pod weight by $24.6 \%$, and the 100 -seed weight by $8.5 \%$. Ravikumar (2012) also revealed that inoculating both Vigna mungo and Vigna radiata varieties with rhizobia resulted in greater plant height, number of nodules, number of roots, shoot growth, number of leaves, number of pods, length of pods, fresh weight, and seed weight than those of their corresponding controls.

In chickpea, significant improvement in the grain yields and protein contents in the grain and straw were reported following the inoculation of chickpea genotypes with dual microbial fertilizers of rhizobia and phosphate-solubilizing bacterial inoculants (Tagore et al., 2013, 2014). John (2015) reported about $16.15-27.50 \%$ grain yield increment in two dry bean (Phaseolus vulgaris) cultivars due to rhizobial inoculation. A significant increment in grain yields of soybean due to inoculation with two isolates (SB6B1 and legumfix) of Bradyrhizobium inoculants in Ethiopia was reported by Fituma (2015). Ronner et al. (2016) showed mean grain yield increments of $1.75,1.42$, and $1.42 \mathrm{t} / \mathrm{ha}$ by inoculation and application of $\mathrm{P}$ fertilizer, seed inoculation alone, and application of sole $\mathrm{P}$ fertilizer, respectively, in soybean. Santos et al. (2019) delineated that inoculation of Bradyrhizobium in soybean resulted in mean increases of $8.4 \%$ in grain yield compared with the naturalized population and that inoculation of common bean with Rhizobium tropici increased yield by $8.3 \%$ (Table 2). Yield increments can vary between legume species and rhizobial strains used due to specific cropping conditions such as soil composition, temperature, site, and environmental conditions.

In their study, Ali et al. (2000) revealed that the inoculation of mung bean (Vigna radiata L.) with rhizobia significantly increased the nodulation, growth, and components of yield like the number of pods bearing branches per plant, number of pods per plant, number of seeds per pod, and 1,000-seed weight. Similar reports were stated by Nyoki and Ndakidemi (2014) in cowpea upon inoculation with Bradyrhizobium japonicum. The increment in the root nodulation, growth, yield components, and yield of legumes by inoculation can be accredited to higher nodulation and further nutrient availability, which resulted in vigorous plant growth and development, and accumulation of dry matter leading to 


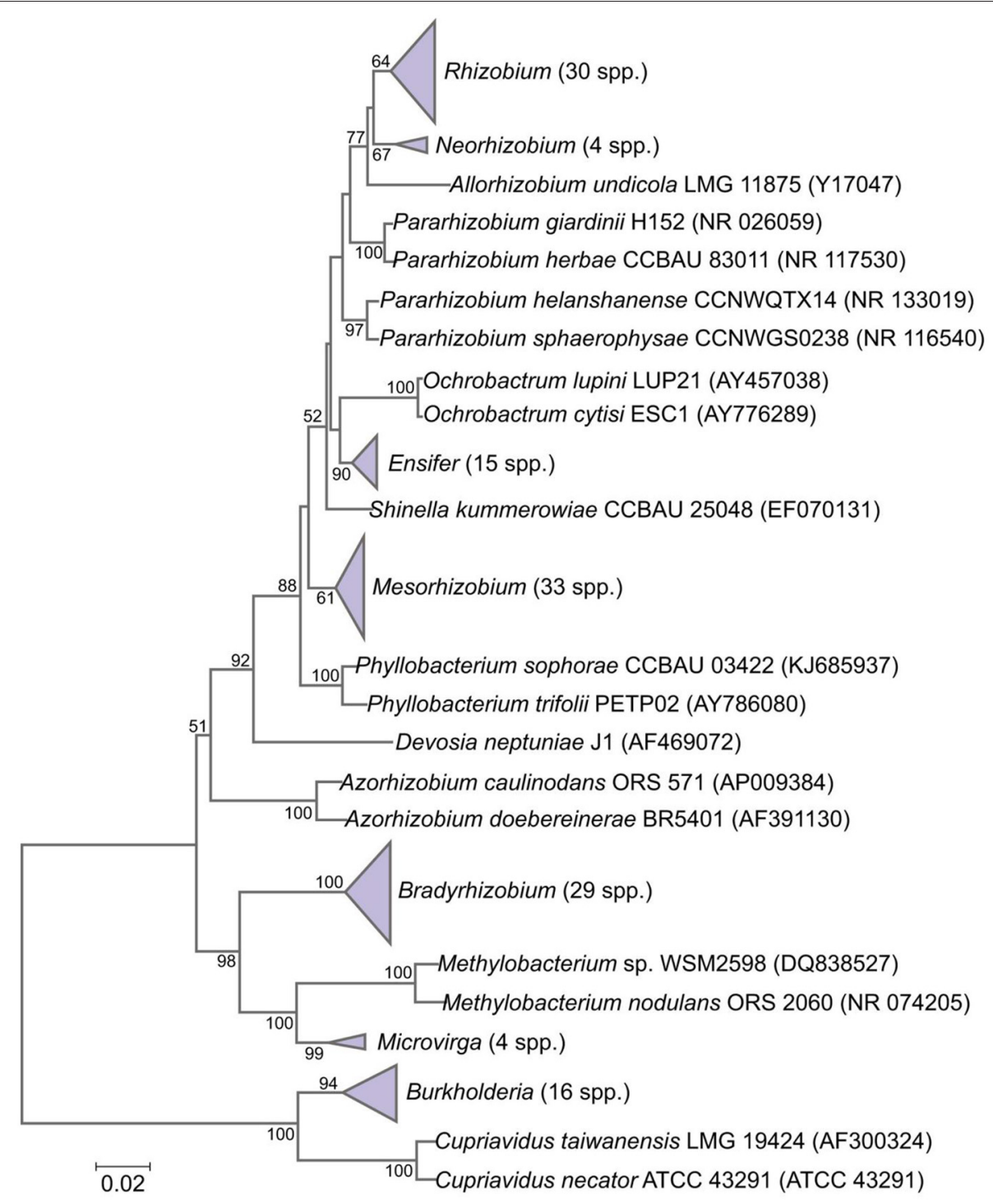

FIGURE 2 | Phylogenetic tree presenting the relationships among currently described genera and species of Alpha- and Beta-rhizobia based on aligned sequences of the 16S rRNA gene (1,341-bp internal region). Adapted from Sprent et al. (2017).

higher seed yields (Namvar et al., 2013; Uddin et al., 2014).

Furthermore, Shahid et al. (2009) revealed that soybean seed production can be increased by $70-75 \%$ when the right rhizobial strains are used to inoculate the crop. Ahiabor et al. (2014) and Rechiatu et al. (2015) showed significant increases in the grain yield of soybean after rhizobial inoculation. Similarly, Ibrahim et al. (2011) stated increased yield and components of the yield of soybean by inoculating the seeds with the rhizobial strain. This could be attributed to higher root nodulation and nitrogen fixation due to inoculation, which eventually increased pod number per plant, and thus higher grain yields (Singh and Singh, 2018). In their study, Nyoki and Ndakidemi (2014) presented that plants inoculated with rhizobia provided significantly greater seed and stover yield than the uninoculated control and suggested the reason as high nodulation which resulted in improved nitrogen fixation and accordingly higher seed and stover yield. Bambara and Ndakidemi (2010) also revealed that rhizobial inoculation significantly improved the yield components and yields such as pods number per plant, seed number per pod, seed number per plant, 100-seed weight, and seed yield as compared to the uninoculated control.

Improvements in legume yield have also been reported with the co-inoculation of different rhizobia resulting from diverse mechanisms of action. Jesus et al. (2018) have shown yield improvement in common bean following co-inoculation with Rhizobium tropici CIAT 899, Bradyrhizobium diazoefficiens USDA 110 (formerly Bradyrhizobium japonicum USDA 110), and Bradyrhizobium elkanii 29w. These authors revealed that Bradyrhizobium spp. improved the symbiosis effectiveness of 
TABLE 2 | An increase in grain yield of different legume species due to inoculation with specific rhizobial strains.

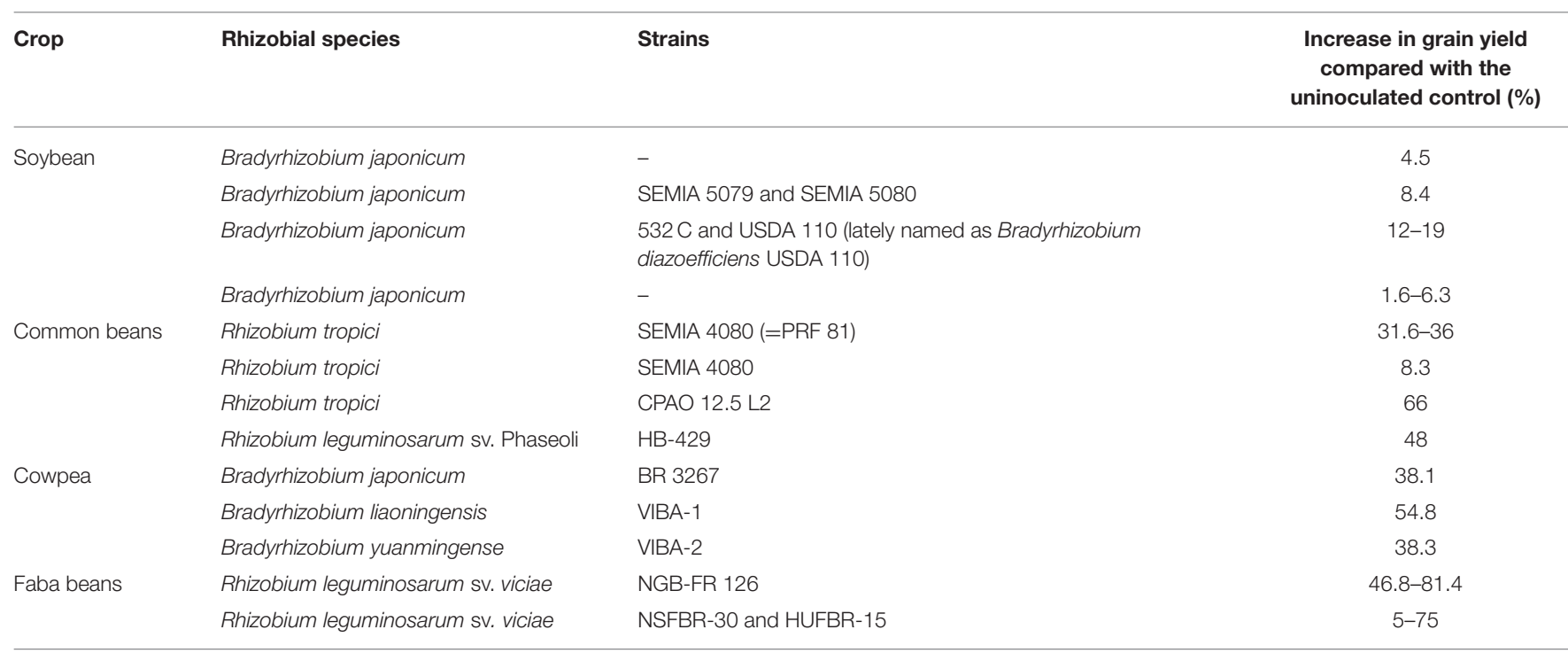

Modified and adapted from Santos et al. (2019).

Rhizobium, resulting in a higher number of nodules, $\mathrm{N}$ accumulation, and overall biomass production. The mechanism behind this positive co-inoculation effect was suggested by Santos et al. (2019) as the co-inoculated rhizobia produced signaling molecules such as nodulation factors (Nod-factors) and polysaccharides that stimulated root nodulation and improved the efficiency of biological nitrogen fixation.

The differences in inoculation responses have been reported in different studies attributing to differences in ecological conditions, crop variety, and the type of inoculant and method of inoculation used; as well as legume response to rhizobial inoculation is reported to be highly unpredictable but variable and site-specific. Moreover, a 5-year comprehensive project by the biological nitrogen fixation in tropical agricultural legumes (NifTAL) project which was aimed at determining the benefits of rhizobial inoculants application for legumes shows clear benefits associated with inoculation. The majority of the 228 standardized field trials conducted in more than 20 countries with 19 legume species gave a significant response to the inoculation of rhizobia when the experiments were carried out under farmers' fields and intensive agronomic management with higher agricultural inputs (Singleton et al., 1992). The amount of increment (in percentage) in grain yield of various legume crops in response to rhizobial inoculation under different agroclimatic conditions as adapted from Bhowmik and Das (2018) is presented in Table 3.

Absences of responses to inoculation of rhizobia have also been reported in some legumes and under different environments (Giller, 2001). These can be accredited to the inherent characteristics of both the host legume plant and the rhizobial species used, as well as the unlimited sensitivity of the fixation process to different environmental stresses such as soil acidity, high temperatures, soil dryness, soil salinity, and low soil fertility (Brockwell et al., 1991; Graham et al., 1994; Wolde-meskel et al., 2018). Egamberdieva and Adesemoye (2016) indicated that there is variability in the effectiveness of inoculants when used in different conditions or cropping systems and the success of rhizobial inoculants applied as a plant growth promoter and/or biocontrol agents to various conditions depends on the collection strategy and screening process. Besides, the success of rhizobial inoculation is restricted by the existence of highly competing native rhizobia which outcompetes and presents a barrier against nodule formation and nodulation by the introduced rhizobial strain (Thies et al., 1991). Resident soil rhizobia including native rhizobia and those naturalized through past inoculation may have an impact on inoculation success through their impact on competence for nodule occupancy with the inoculated strains of rhizobia (Denton et al., 2002). According to Thies et al. (1991), the response of several legumes to rhizobial inoculation depends largely on the population of native soil rhizobia, available soil nitrogen, and the crop's nutrient demand.

\section{Rhizobial Inoculation Improves Nutrient Availability and Uptake by Plants}

Bioavailability and uptake of elemental plant nutrients such as nitrogen, phosphorus, potassium, calcium, magnesium, and sulfur are very imperative for the growth and development of plants, especially where diverse cropping systems involving legumes are practiced. The uptake of these nutrients by plants depends fundamentally on the quantity, concentration, and activities in the soil rhizosphere, and the capability of the soil to restore them in the soil's solution. Nutrient uptake by the plant is essential for plant growth and function including symbiotic nitrogen fixation processes. Although total nutrient uptake by legume crops depend on the yield obtained, which can be varied with cropping season, type of variety, soil condition, and crop agronomic practices (Tairo and Ndakidemi, 2014), it has been reported that inoculation of legumes with rhizobia significantly 
TABLE 3 | The increment (\%) in the grain yield of legumes in response to rhizobial inoculation under different agroclimatic conditions.

\begin{tabular}{|c|c|c|}
\hline Crop name & Location (country) & $\begin{array}{c}\text { Increment (\%) in } \\
\text { grain yield over } \\
\text { uninoculated }\end{array}$ \\
\hline \multirow[t]{4}{*}{ Vigna mungo } & Pudukkottai, Tamil Nadu & $4.0-21.0$ \\
\hline & Dholi, Bihar & $11.0-29.0$ \\
\hline & Pantnagar, Uttar Pradesh & $17.0-21.0$ \\
\hline & Varanasi, Uttar Pradesh & $0.14-2.32$ \\
\hline \multirow[t]{7}{*}{ Vigna radiate } & Lam, Andhra Pradesh & $1.4-75.0$ \\
\hline & Delhi & $10.0-49.0$ \\
\hline & Pantnagar, Uttar Pradesh & $4.0-15.0$ \\
\hline & Dantiwada, Gujarat & $0-3.5$ \\
\hline & Hisar, Haryana & $<1.0$ \\
\hline & Kovilpatti, Tamil Nadu & 12.5 \\
\hline & Jodhpur, Rajasthan & $<1.0$ \\
\hline \multirow[t]{7}{*}{ Cajanus cajan } & Hisar, Haryana & $5.0-25.0$ \\
\hline & Pantnagar, Uttar Pradesh & $2.0-25.0$ \\
\hline & Sardarkrushinagar, Gujarat & $9.0-21.0$ \\
\hline & Sehore, Madhya Pradesh & 13.0-29.0 \\
\hline & Rahuri, Maharashtra & $20.0-41.0$ \\
\hline & Hyderabad, Telangana & $<1.0$ \\
\hline & Kovilpatti, Tamil Nadu & $40-47.2$ \\
\hline \multirow[t]{11}{*}{ Cicer arietinum } & Varanasi, Uttar Pradesh & $4.0-19.0$ \\
\hline & Hisar, Haryana & $24.0-43.0$ \\
\hline & Dholi, Bihar & $25.0-42.0$ \\
\hline & Delhi & $18.0-28.0$ \\
\hline & Sehore, Madhya Pradesh & $20.0-41.0$ \\
\hline & Dahod, Gujarat & $33.0-67.0$ \\
\hline & Badnagar, Maharashtra & $8.0-12.0$ \\
\hline & Kovilpatti, Tamil Nadu & $4.0-8.2$ \\
\hline & Indore, Madhya Pradesh & $4.0-8.2$ \\
\hline & Rewa, Madhya Pradesh & $2.9-22.0$ \\
\hline & Varanasi, Uttar Pradesh & $0-13.5$ \\
\hline Lens culinaris & Pantnagar, Uttar Pradesh & $4.0-26.0$ \\
\hline \multirow[t]{3}{*}{ Cyamopsis } & Agra, Uttar Pradesh & $11.2-16.6$ \\
\hline & Jhansi, Uttar Pradesh & $3.7-8.6$ \\
\hline & Jodhpur, Rajasthan & $<1.0$ \\
\hline \multirow[t]{2}{*}{ Macrotyloma } & Bangalore, Karnataka & $<1.0$ \\
\hline & Hyderabad, Telangana & $<1.0$ \\
\hline Vigna unguiculata & Hyderabad, Telangana & $<1.0$ \\
\hline Dolichos sp. & Hyderabad, Telangana & $<1.0$ \\
\hline Vigna aconitifolia & Jodhpur, Rajasthan & $<1.0$ \\
\hline \multirow[t]{3}{*}{ Glycine max } & Kovilpatti, Tamil Nadu & $0.0-5.0$ \\
\hline & Indore, Madhya Pradesh & $0.0-1.6$ \\
\hline & Rewa, Madhya Pradesh & $0.0-5.0$ \\
\hline
\end{tabular}

Adapted from Bhowmik and Das (2018).

increases the availability and uptake of phosphorus, potassium, calcium, and magnesium in different organs of the plants (Makoi et al., 2013).

A study by Ndakidemi et al. (2011) showed that rhizobial inoculation improved the availability and uptake of plant nutrients such as $\mathrm{P}, \mathrm{K}, \mathrm{Mg}, \mathrm{Ca}, \mathrm{S}, \mathrm{Fe}, \mathrm{Mn}, \mathrm{Zn}, \mathrm{Cu}, \mathrm{B}$, and $\mathrm{Mo}$ in different legumes. Makoi et al. (2013) reported that rhizobial inoculation significantly improved the uptake of nutrients such as $\mathrm{P}, \mathrm{K}, \mathrm{Ca}$, and $\mathrm{Mg}$ in different plant parts such as leaves, shoots, roots, and pods of common beans (Phaseolus vulgaris L.). Allito et al. (2020) indicated that inoculation of faba bean with diverse rhizobial strain caused a significant improvement in nitrogen uptakes which ranged from 194.7 to $309.6 \mathrm{~kg} \mathrm{~N} \mathrm{ha}^{-1}$ as compared to the un-inoculated control as well as soil nitrogen balance is also increased following inoculation of rhizobia. These authors indicated that the increment in the nitrogen uptake and soil nitrogen balance is mainly accredited to improved nitrogen fixation.

Inoculation of legumes with rhizobia can also noticeably enhance the availability and uptake of phosphorus in legumes. Tairo and Ndakidemi (2014) revealed that cowpea [Vigna unguiculata (L.) Walp] inoculation with Bradyrhizobium japonicum significantly enhanced uptake of the phosphorus which might be accredited to indirect effects of inoculation of Bradyrhizobium japonicum on plant growth and activities of the rhizosphere. On the other hand, increased root capacities to absorb nutrients (Ziadi et al., 2007) and mobilization of phosphorus caused by improved extracellular phosphatase activity (Agren et al., 2012) are the supreme reasons responsible for enhanced availability and uptake of phosphorus. Regar et al. (2017) indicated that rhizobial inoculation improved the development of roots and the availability of more nutrients in soybean due to boosted growth and development of the plant. Higher phosphorus uptake due to rhizobial inoculation is accredited to the capacity of introduced rhizobia to solubilize precipitated phosphorus components thereby improving the availability and uptake in plants (Fatima et al., 2007). The nitrogen and phosphorus uptakes by different parts of faba bean inoculated with six different strains of rhizobia and noninoculated plants provided with and without $\mathrm{N}$ fertilizer as $+\mathrm{N}$ and $-\mathrm{N}$ controls, respectively, are shown in Table 4.

Rhizobial inoculation can also improve the contents of nutrients in plants. According to Matse et al. (2020), the separate inoculation of two Rhizobium species and their co-inoculation significantly improved the $\mathrm{N}, \mathrm{P}$, and $\mathrm{K}$ contents in roots and shoots of white clover as compared to the non-inoculated control. Sahai and Chandra (2011) revealed higher nitrogen and phosphorus uptake and content in both shoot and grain when legume is inoculated with Mesorhizobium ciceri in contrast to uninoculated control. Further, Kaur et al. (2015) showed that chickpea inoculation with Mesorhizobium sp. resulted in 61.1 and $11.4 \%$ greater grain $\mathrm{N}$ and $\mathrm{P}$ content, respectively, due to the improved nitrogen fixation as well as improvement in root growth and root behavior which favorably increased nutrient acquisition.

\section{RHIZOBIAL INOCULANTS AS A BIOCONTROL AGENT OF PLANT DISEASES}

Microbial pathogens such as fungi, bacteria, viruses, and nematodes are the farmer's enemies as they are the foremost destroyers of crops production leading to economic losses. 
TABLE 4 | The nitrogen and phosphorus uptaking by roots, haulms, and grains of faba bean inoculated with six different Rhizobium strains.

\begin{tabular}{|c|c|c|c|c|c|c|c|c|}
\hline Treatments & \multicolumn{4}{|c|}{ Nitrogen uptake $\left(\mathrm{kg} \mathrm{N} \mathrm{ha}^{-1}\right)$} & \multicolumn{4}{|c|}{ Phosphorus uptake (kg P ha-1) } \\
\hline NSFBR-15 & $28.50^{\mathrm{a}}$ & $156.60^{a}$ & $124.50^{\mathrm{a}}$ & $309.60^{a}$ & $7.40^{\mathrm{a}}$ & $24.50^{\mathrm{a}}$ & $39.90^{a}$ & $71.80^{\mathrm{a}}$ \\
\hline HUFBR-17 & $25.80^{\mathrm{ab}}$ & $133.50^{\mathrm{ab}}$ & $101.70^{C}$ & $261.10^{b}$ & $5.40^{\mathrm{C}}$ & $16.50^{\text {cd }}$ & $28.00^{b}$ & $49.90^{d}$ \\
\hline NSFBR-12 & $27.20^{\mathrm{ab}}$ & $152.80^{\mathrm{a}}$ & $116.50^{\mathrm{ab}}$ & $296.50^{\mathrm{a}}$ & $6.20 b^{c}$ & $21.50^{a b}$ & $36.70^{a}$ & $64.40^{\mathrm{bc}}$ \\
\hline NSFBR-20 & $25.50^{\mathrm{ab}}$ & $130.10^{\mathrm{b}}$ & $102.30^{c}$ & $257.90^{b}$ & $6.00^{\mathrm{bc}}$ & $18.40 b^{c}$ & $27.30^{\mathrm{b}}$ & $51.70^{d}$ \\
\hline$+\mathrm{N}$ & $23.40^{\mathrm{bc}}$ & $153.50^{a}$ & $106.80^{\mathrm{bc}}$ & $283.80^{\mathrm{ab}}$ & $6.40^{\mathrm{abc}}$ & $24.80^{\mathrm{a}}$ & $29.20^{b}$ & $60.40^{c}$ \\
\hline N & $20.30^{c}$ & $94.40^{c}$ & $80.10^{d}$ & $194.70^{c}$ & $4.00^{d}$ & $13.30^{d}$ & $21.20^{\mathrm{C}}$ & $38.50^{\mathrm{e}}$ \\
\hline CV (\%) & 18.20 & 18.80 & 13.30 & 14.10 & 19.50 & 22.20 & 16.10 & 14.70 \\
\hline
\end{tabular}

Adapted from Allito et al. (2020).

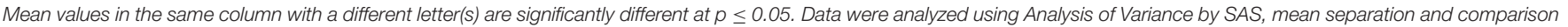
were done using Duncan's Multiple Range Test, and the association among treatment means was done using Pearson correlation test.

The growth performance, yields, quantity, and quality of crops of agronomic importance can be maintained by controlling these microbial pathogens (Shinwari et al., 2019). The usual strategy for the control of pathogens is to apply chemical pesticides which have led to increased concerns over ecological contamination (Martínez-Viveros et al., 2010). The use of these chemical-based products has also affected the human health and microbial population in the soil. Moreover, the long utilization of such chemicals in the agro-systems has led to resistance in microbial pathogens which is one great concern (Yadav et al., 2021). Considering the demand for the health of the environment and sustainable crop production, researchers have suggested an alternative approach to control pathogens. Besides, emerging knowledge revealed the presence of an impressive microbial diversity among all plants and antagonist microorganisms for plant pathogens. As a result, an innovative technique progressively studied and implemented in agricultural production is the use of plant growth-promoting rhizobia as a biocontrol agent to induce plant resistance to pathogenic diseases.

Nowadays, biocontrol of plant diseases is a recognized subdiscipline of plant pathology and the manipulation of the plant rhizosphere by inoculation with biocontrol agents of plant pathogens has presented considerable assurance (Egamberdieva and Adesemoye, 2016). The process of disease suppression and/or control by biocontrol agents is the manifestation of interactivities among the host plant, the biocontrol agent, the pathogen, the microbial community around and on the plant, and the physical environment. In this context, antagonism and biocontrol agents for plant diseases can be presently observed as substitutes to chemical pesticides due to their recognized level of human safety and insignificant ecological impacts (Hemissi et al., 2011). Thus, the use of biocontrol agents is the most feasible and environment-friendly approach to reduce agricultural chemical input and their residues in the environment. Hence, this approach is effective in improving the plant resistance to plant pathogens and can play an imperative role in the development of sustainable agricultural systems.

Among plant growth-promoting microorganisms, rhizobial strains are rhizospheric bacteria of great agricultural and ecological importance, which can grant numerous beneficial effects in improving plant growth and development. The inoculation of plants, particularly legumes, with these groups of microorganisms is found to be effective as a biocontrol of various plant diseases. Although the fundamental reasoning behind the inoculation of rhizobia on crops is to increase nitrogen availability, rhizobial strains have also been found to induce plant resistance to various diseases and reduce the severity of several diseases in leguminous and nonleguminous plants (Volpiano et al., 2019). Das et al. (2017) described that many species of rhizobia were found to prevent the growth of various soil-borne pathogens such as Macrophomina phaseolina, Rhizoctonia solani, and Fusarium spp. in both leguminous and non-leguminous plants. For instance, application of Sinorhizobium meliloti, Rhizobium leguminosarum bv. viceae, and Bradyrhizobium japonicum as seed coating or soil drenching inhibited the disease incidence and severity of Macrophomina phaseolina, Rhizoctonia solani, and Fusarium spp. in okra plants.

A study by Deshwal et al. (2003) indicated the inhibition of growth of seven pathogenic microorganisms of soybean by 20 strains of rhizobia in which the fast-growing rhizobial strains suppressed the growth of the pathogenic organisms. The use of rhizobial strains as biocontrol agents is an environmentfriendly approach and offers an opportunity to reduce the use of pesticides in agricultural production. Besides, rhizobial inoculants are available in the market globally leading to substantial contributions to the productivity of agricultural systems. This part of the review presents available information on the use of rhizobial strains as biocontrol agents and mechanisms of action for control and suppression of diseases caused by plant pathogens mainly focusing on fungi, bacteria, viruses, and nematodes. 
TABLE 5 | The interaction effects of different kinds of rhizobial isolates and time of application on the suppression of Fusarium solani incidence and severity under greenhouse conditions.

\begin{tabular}{|c|c|c|c|c|c|}
\hline Treatments & Time & Incidence & $\begin{array}{l}\text { Incidence reduction } \\
\text { (\%) }\end{array}$ & Severity & $\begin{array}{c}\text { Severity } \\
\text { reduction (\%) }\end{array}$ \\
\hline \multirow[t]{3}{*}{ Rhizobial isolate "JU26(1)" } & Before & $(50) 45.00^{b} \pm 0.00$ & 50.00 & $(55.5) 48.10^{\mathrm{cd}} \pm 0.00$ & 37.50 \\
\hline & At time & $(50) 45.00^{b} \pm 0.00$ & 50.00 & $(61.1) 51.40^{\mathrm{bc}} \pm 0.00$ & 27.70 \\
\hline & After & $(50) 45.00^{b} \pm 0.00$ & 50.00 & $(64.8) 53.60^{\mathrm{b}} \pm 1.90$ & 27.00 \\
\hline \multirow[t]{3}{*}{ Rhizobial isolate “JU15(2)" } & Before & (25) $30.00^{c} \pm 0.00$ & 75.00 & $(38.8) 38.50^{e} \pm 0.00$ & 56.30 \\
\hline & At time & (25) $30.00^{c} \pm 0.00$ & 75.00 & $(51.8) 46.00^{d} \pm 1.80$ & 41.60 \\
\hline & After & $(41) 40.00^{b} \pm 8.60$ & 59.00 & (55.5) $48.10^{\mathrm{cd}} \pm 0.00$ & 37.50 \\
\hline \multirow[t]{3}{*}{ Rhizobial isolate "Ho-1WG" } & Before & (25) $30.00^{c} \pm 0.00$ & 75.00 & $(31.4) 34.00^{f} \pm 2.00$ & 64.60 \\
\hline & At time & (25) $30.00^{c} \pm 0.00$ & 75.00 & $(38.5) 38.50^{\mathrm{e}} \pm 0.00$ & 56.60 \\
\hline & After & $(50) 45.00^{b} \pm 0.00$ & 50.00 & $(57.3) 49.20^{\mathrm{cd}} \pm 1.80$ & 35.40 \\
\hline \multirow[t]{3}{*}{ Combination } & Before & (0) $1.40^{d} \pm 0.00$ & 100.00 & $(23.7) 29.10^{9} \pm 1.80$ & 73.30 \\
\hline & At time & (0) $1.40^{d} \pm 0.00$ & 100.00 & $(31.2) 33.90^{f} \pm 2.30$ & 64.80 \\
\hline & After & (25) $30.00^{c} \pm 0.00$ & 75.00 & $(35.1) 36.30^{e f} \pm 1.90$ & 60.40 \\
\hline Control (diseased) & Before & $(100) 88.6^{a} \pm 0.0$ & 0.00 & $(88.8) 70.40^{\mathrm{a}} \pm 0.00$ & 0.00 \\
\hline Mean & & $(35.85) 35.50 \pm 0.60$ & 64.10 & $(44.40) 48.73 \pm 1.04$ & 44.80 \\
\hline CV (\%) & & 5.30 & & 2.80 & \\
\hline
\end{tabular}

Source: Tamiru and Muleta (2018).

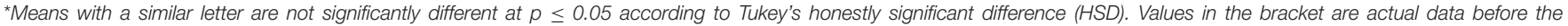

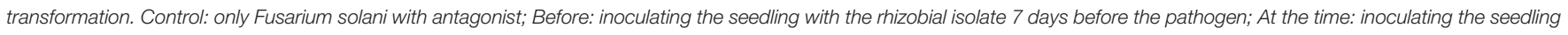

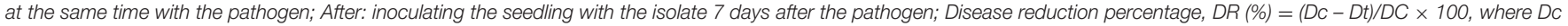
is a disease on the control plants and Dt is a disease on the treated plants.

\section{Rhizobia as a Biocontrol Agent of Plant Diseases Caused by Fungi}

Rhizobia were reported to parasitize, distort and inhibit the hyphae and reproductive structures of fungi, and antagonize fungal pathogens by the secretion of hydrolytic enzymes (Volpiano et al., 2019). Antoun et al. (1978) evaluated the antagonistic ability of 49 Sinorhizobium meliloti strains against Fusarium oxysporum and showed that the strains suppressed the disease notwithstanding their symbiotic effectiveness and the inhibition of the fungal growth varied from 5 to $50 \%$. Kelemu et al. (1995) reported that 15 Bradyrhizobium sp. strains evaluated in dual cultures exhibited the capacity to suppress the mycelial growth of Rhizoctonia solani. Chao (1990) evaluated six rhizobial strains for their disease antagonistic ability against ten fungi isolates and revealed that all the tested Rhizobium strains reduced the growth of fungi.

According to Ehteshamul-Haque and Ghaffar (1993), Rhizobium leguminosarum, Sinorhizobium meliloti, and Bradyrhizobium japonicum are testified to significantly hinder the growth of pathogenic fungi such as Macrophomina phaseolina (Tassi) Gold, Rhizoctonia solani Kuhn, and Fusarium species in both legume and non-leguminous plants. Moreover, Tamiru and Muleta (2018) indicated that Faba bean inoculation with rhizobial isolates suppressed the radial growth of Fusarium solani under in vitro conditions and the average disease reduction for combinations of rhizobial isolates was $45.1 \%$ as compared to $29.2 \%$ for individual strains and the highest disease severity (73.3\%) suppression was detected with inoculation of a combination of Rhizobium isolates before the appearance of the pathogen (Table 5). As a result, the mixture of rhizobial strains as biocontrol agents helps to defend against a broader range of pathogens, acclimatize to the ecological fluctuations, and improve the genetic diversity of biocontrol systems. In addition, it also allows the perseverance of the biocontrol agents for an extended period in the rhizosphere, exploitation of a broader array of biocontrol mechanisms which improve the efficiency and reliability of biocontrol and offer a mixture of several mechanisms of biocontrol.

Studies have also revealed that white rot disease (Sclerotinia sclerotiorum) of Brassica campestris can be controlled by inoculation with Mesorhizobium loti in which the growth of disease was suppressed by $75 \%$ after extended incubation (Chandra et al., 2007) (Figure 3A), sheath blight of rice can be controlled by inoculation with Rhizobium leguminosarum bv. phaseoli strain RRE6 and bv. Trifolii strain ANU843 (Mishra et al., 2006), and Pythium root rot of sugar beet can be controlled by inoculation with Rhizobium leguminosarum viciae (Bardin et al., 2004). Dubey et al. (2012) assessed Bradyrhizobium sp. isolates of black gram for antifungal activities against Macrophomina phaseolina and revealed that two rhizobial isolates (VR2 and VR1) were capable of reducing the Macrophomina phaseolina mycelial growth by 71.5 and $50.5 \%$ in dual cultures and by 37.6 and $49.2 \%$ in cellfree cultures, respectively (Figure 3B). Gopalakrishnan et al. (2015) also revealed that the inoculation of Bradyrhizobium japonicum, Rhizobium leguminosarum, and Rhizobium meliloti can be a biocontrol of plant pathogenic fungi that infect okra and sunflower such as Macrophomina phaseolina, Rhizoctonia solani, and Fusarium solani. Kumar et al. (2011) isolated five rhizobial strains (TR1-TR5) from fenugreek root nodules and 


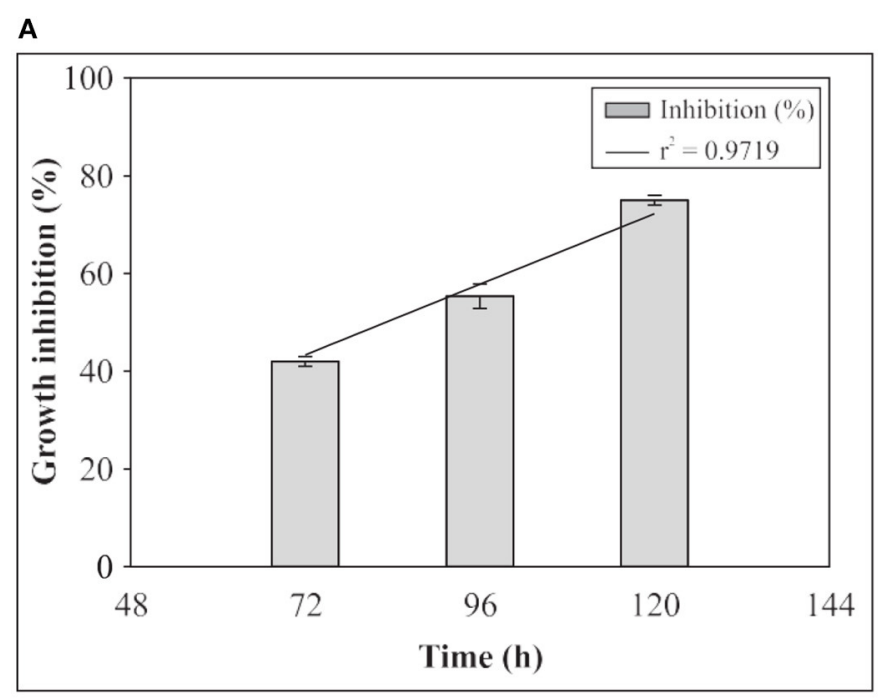

\section{B}

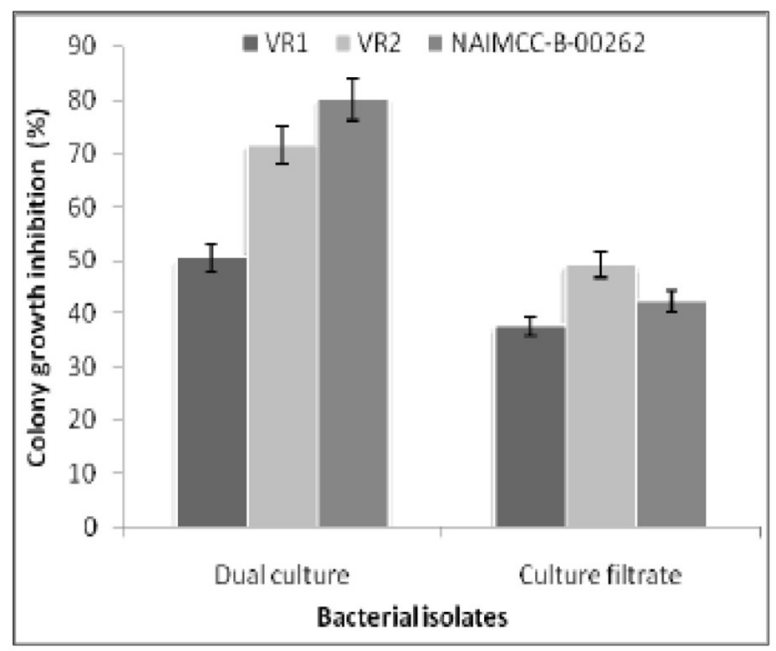

FIGURE 3 | (A) The inhibition of growth of Sclerotinia sclerotiorum by Mesorhizobium loti MP6 in vitro at different days of incubation (Chandra et al., 2007). (B) The inhibition of growth of Macrophomina phaseolina in vitro by Bradyrhizobium isolates in dual culture and by cell-free extract at $28 \pm 1^{\circ} \mathrm{C}$ (Dubey et al., 2012 ).

reported that three isolates (TR1, TR2, and TR4) suppressed the growth of Fusarium oxysporum, resulting in loss of structural integrity of the mycelium, hyphal perforation, lysis of hyphae, fragmentation, and degradation. According to Hemissi et al. (2011), the reduction of fungal growth in vitro by rhizobia and subsequent formation of zones of suppression were probably a result of the metabolites released into the culture medium by rhizobia. Microscopic investigations also revealed that rhizobial inoculation leads to abnormal intercalary swelling, unfolding, tip deformation, lysis of hyphae, and degeneration of cytoplasm of fungi such as Rhizoctonia solani, Fusarium oxysporum, Sclerotinia sclerotiorum, and Macrophomina phaseolina due to interaction with rhizobia (Deshwal et al., 2003).

\section{Rhizobia as a Biocontrol Agent of Plant Diseases Caused by Bacteria}

Like rhizobia, plant-pathogenic bacteria establish companionable interactions with plants to obtain nutrients from the host plants upon the colonization, and both rhizobia and plant-pathogenic bacteria implemented similar strategies to colonize, invade, and form a chronic infection in the host plants (Volpiano et al., 2019). Different studies on the effects of rhizobia on diseases caused by plant-pathogenic bacteria demonstrated that rhizobia have biocontrol properties against plant-pathogenic bacteria. Osdaghi et al. (2011) indicated that inoculation of common bacterial blight (CBB)-susceptible cultivar and tolerant lines of common bean with Rhizobium leguminosarum bv. phaseoli significantly reduced the disease severity of $\mathrm{CBB}$ under both greenhouse and field experiments. Díaz-Valle et al. (2019) delineated that the inoculation of common bean with Rhizobium etli inhibited halo blight severity as compared to plants not inoculated with the symbiont and indicated that the size of foliar pathogen lesion was $75 \%$ lesser in the Rhizobium etli-treated plants than in the uninoculated plants. Osdaghi et al. (2011) assessed the inoculation of the Rhizobium leguminosarum bv. phaseoli strain on $\mathrm{CBB}$ of common bean caused by Xanthomonas axonopodis pv. phaseoli under greenhouse and field conditions and delineated that Rhizobium leguminosarum bv. phaseoli significantly reduced disease severity. Rhizobial strains such as Rhizobium leguminosarum bv. trifolii, Rhizobium leguminosarum bv. viciae, Rhizobium meliloti, Rhizobium trifolii, Sinorhizobium meliloti, and Bradyrhizobium japonicum have been reported to produce antibiotics and cell-wall-degrading enzymes that can hinder the phytopathogenic bacteria (Gopalakrishnan et al., 2015). Díaz-Valle et al. (2019) also showed that rhizobial inoculation facilitated greater and more rapid activation of defense-related genes following infection with the pathogenic bacteria and suggested that inoculation is imperative for a cellular mechanism of ISR in plants.

\section{Rhizobia as a Biocontrol Agent of Plant Diseases Caused by Viruses}

To date, the investigations regarding rhizobia and viruses have been mainly concerned with the effect of viral diseases on the nodulation process, nitrogen fixation, and subsequent nitrogen availability to the plants and nutrient content in plants. However, studies have revealed that rhizobial inoculation has contributed to the biocontrol of plant viral diseases. Elbadry et al. (2006) showed significant inhibition in bean yellow mosaic potyvirus (BYMV) disease in broad bean in which the incidence was reduced from $91.33 \%$ (infected control) to $43 \%$ and $27.7 \%$ when inoculated with rhizobia and Pseudomonas FB11 strains, respectively, showing that rhizobia are key biocontrol agents against plant viral diseases. Singh and Srivastava (1983) suggested that the increase in availability and nutrition of nitrogen following inoculation of Rhizobium phaseoli strain Dangeard 
affected the replication and symptomatic appearance of common bean mosaic virus in mung beans (Vigna radiata). Further, Elbadry et al. (2006) proved the presence of ISR against BYMV in broad bean inoculated with Rhizobium leguminosarum bv. viciae.

\section{Rhizobia as a Biocontrol Agent of Plant Diseases Caused by Nematodes}

The association of rhizobia with plant nematodes in the rhizosphere and the beneficial effect of rhizobia on nitrogen fixation and plant nutrition have led to studies on the potential effect of nematode parasitism on nodulation and symbiotic nitrogen fixation (Taha, 1993) and the inhibition effect of rhizobial inoculation on plant nematodes (Khan et al., 2017). Consequently, rhizobial strains can act as biocontrol agents of diseases caused by parasitic nematodes through direct and/or indirect mechanisms in both legumes and non-legumes (Volpiano et al., 2019), and the galling, egg mass production, and soil population of the nematode can be suppressed by the treatment of rhizobia (Khan et al., 2017). Noreen et al. (2016) reported the reduction of root-knot nematode in chickpea following inoculation with rhizobia and suggested rhizobial inoculation as a biocontrol of root-knot nematode. Volpiano et al. (2019) revealed that inoculation of Rhizobium can decrease about $96 \%$ of galls in roots of eggplant (Solanum melongena) infected with Meloidogyne incognita. Siddiqui et al. (2007) suggested Rhizobium inoculation as the most efficient biocontrol of nematodes as inoculation of Rhizobium endorsed the decrease from 72 (infested control) to 40 galls per root systems and 14,960 (infected control) to 7,520 nematodes per kilogram of soil, apart from causing a larger increase in plant growth in the absence of Meloidogyne javanica.

Besides, Ashoub and Amara (2010) reported the ability of the Rhizobium isolate of broad bean (Vicia faba) to attain $100 \%$ mortality of Meloidogyne incognita juvenile in vitro at $72 \mathrm{~h}$. Studies have revealed that the cyst nematode of potato can be controlled by inoculation with Rhizobium etli strain G12 (Reitz et al., 2000). Khan et al. (2017) reported $12 \%$ to $18 \%$ mortality in the nematode juveniles due to the culture and culture filtrate of the rhizobial strains and suggested that the inhibition in the hatching and survival of nematode larvae and mortality in the nematode juveniles were apparently due to the toxic metabolites synthesized by the bacteria. According to Sidhu (2018), the most susceptible stages of plant-parasitic nematodes to manage with biocontrol are the eggs and second-stage juveniles as these life stages survive outside of the plants, especially in water films in soil particles, providing biocontrol agents the opportunity to interact, infect, and parasitize the nematodes. Consequently, the life process and cycle of the nematodes can be interrupted, resulting in decreased population density and successful control when the eggs and second-stage juveniles of the plant-parasitic nematodes are controlled.

Rhizobia are reported to show active responses against nematodes by possessing different modes of actions such as impeding plant-nematode recognition, hindering nutrient uptake, activating systemic resistance against them, and undergoing direct inhibition by producing various enzymes, toxins, and metabolites (Khanna et al., 2019). Hallmann et al. (2001) reported a significant reduction in the number of potato root galls formed by Meloidogyne incognita following inoculation with Rhizobium etli G12 and G12 (pGT-trp) in which the number of galls was reduced by 34 and 39\%, respectively, compared with plants treated with only Meloidogyne incognita. Mahdy et al. (2001) also indicated nematode control in different vegetables (tomato, cucumber, and pepper) and field crops (soybean and cotton) by Rhizobium etli G12 with a decrease in galling ranging from $17 \%$ for cotton to $50 \%$ for tomato and a significant decrease in the number of egg masses ranging from $37 \%$ for soybean to $70 \%$ for pepper.

Nematodes enter roots via the zone of elongation and differentiation, which is also a zone preferably colonized by biocontrol agents, and alterations in the physiology of plant following nematode infection might also create favorable conditions for rhizobial inoculant well (Hallmann et al., 1997). Following the inoculation, rhizobia can actively penetrate plant tissues using hydrolytic enzymes like cellulase and pectinase (Hallmann et al., 1997), or they can penetrate within galled tissue via the wounds caused by juveniles and move from the galled tissue to the stem base, thereby leaking, intercepting, and reducing the nutrients available to the nematode, hence interfering with nematode development and decreasing egg production (Hallmann et al., 2001). Another aspect of rhizobia-nematode interaction is that root nodulation may limit the pathogenesis of root-knot nematode, resulting in a significant decline in the galling and reproduction of nematodes, particularly the Meloidogyne spp. (Taha, 1993). According to Khan et al. (2017), a toxin named "rhizobitoxine" is produced by Bradyrhizobium japonicum, which may negatively affect the nematode pathogenesis, and bacteriocin was also produced by rhizobial strains, which may be involved in the reduction of nematode in plants. Reitz et al. (2000) also confirmed that lipopolysaccharides secreted by Rhizobium etli strain G12 activated ISR to infection in potato roots against the potato cyst nematode Globodera pallida.

\section{Mechanisms of Action for Biocontrol and Suppression of Plant Disease by Rhizobia}

In comparison to the other biocontrol agents, rhizobial inoculants play an essential role in agricultural production through their capacity of symbiotic nitrogen fixation, solubilization of phosphorus and biocontrol, and suppression of plant diseases (Compant et al., 2005; Hemissi et al., 2011; Gopalakrishnan et al., 2015; Khan et al., 2017; Volpiano et al., 2019). Numerous mechanisms have been identified to be employed by rhizobia for biocontrol and suppression of plant diseases. According to Martínez-Viveros et al. (2010), enormous mechanisms are involved in rhizobia as a biocontrol, which involves direct antagonism via the production of antibiotics, siderophores, HCN, and hydrolytic enzymes (chitinases, proteases, lipases, etc.) and indirect mechanisms in which the biocontrol agent acts as a probiotic by contending with the pathogen for the infection sites and nutrients, activating 


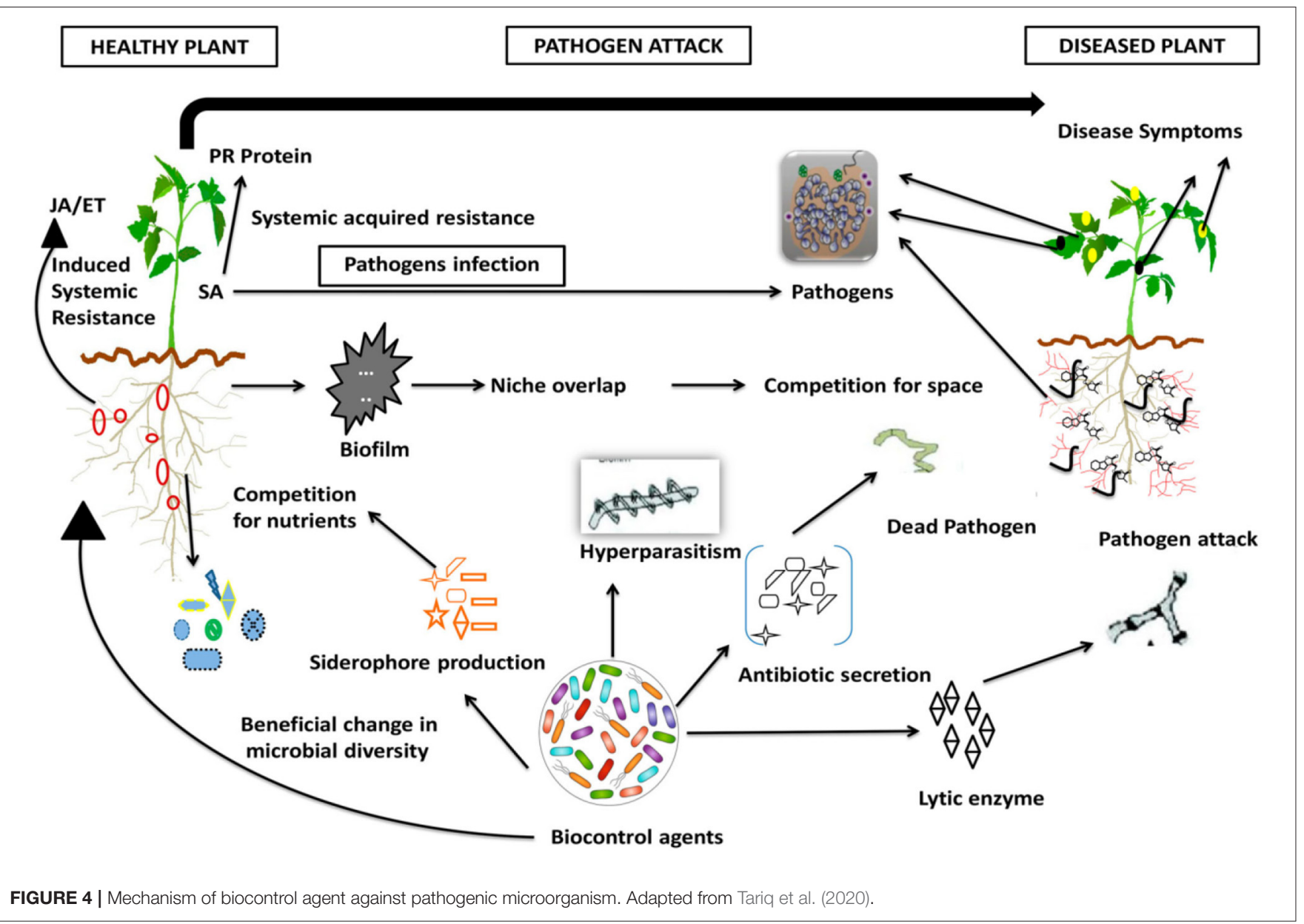

acquired systemic resistance and ISR responses in plants, and modifying hormonal levels in plant tissues. Compant et al. (2005) indicated that aggressive colonization, self-protective retention of the rhizosphere niches, and biocontrol characteristics of rhizobia are facilitated by the production of allelochemicals, including antibiotics, iron-chelating siderophores, lytic enzymes, biocidal volatiles, and detoxification enzymes. Gopalakrishnan et al. (2015) reported that rhizobial inoculants famish the plant pathogens by generating high-affinity siderophores and, thus, limit the growth and development of the pathogens. Besides, Deshwal et al. (2003) stated that the biocontrol mechanisms of rhizobia may involve antibiotics, HCN, and siderophores. Rhizobia also appear to influence the plant defense mechanism by enhancing the production of phytoalexins by plants. According to Tariq et al. (2020), the overall mechanisms of biocontrol depend essentially on antibiosis, competition for nutrients, mycoparasitism, production of hydrolytic enzymes, induction of systemic resistance in host plants, and rhizosphere competence. Numerous mechanisms of biocontrol against plant pathogenic microorganisms are indicated in Figure 4.

Furthermore, Gopalakrishnan et al. (2015) stated the mechanisms of biocontrol employed by rhizobia like competition for plant nutrients, antibiotic production, enzyme production to degrade cell walls, siderophore production, and the synthesis of metabolites such as HCN, phenazines, pyrrolnitrin, viscoinamide, and tensin. According to Ahemad and Kibret (2014), the principal modes of biocontrol properties in the usage of rhizobial inoculants are competition for nutrients, niche exclusion, ISR, and production of antifungal metabolites. In general, seed biopriming and plant inoculation with rhizobia can offer systemic resistance against a broad spectrum of plant pathogens. Das et al. (2017) also stated the mechanisms involved in biocontrol by rhizobia like mycoparasitism, production of antibiotics, antifungal secondary metabolites such as $\mathrm{HCN}$, siderophore production and subsequent competition for iron between pathogens and rhizobia, competition for nutrients, induction of plant defense mechanisms, and plant growth promotion, which decreases vulnerability to pathogenic attack. Diseases of bacterial, fungal, and viral origin and damages caused by nematodes can be decreased by the application of plant growth-promoting bacteria such as rhizobia (Compant et al., 2005). In general, rhizobia-mediated plant growth promotion and biocontrol of diseases occur by the change in the entire microbial community of the rhizosphere niche and through the production of different substances, as indicated in Table 6. 
TABLE 6 | Rhizobial species and substances produced for growth promotion and defense against plant diseases.

\begin{tabular}{ll}
\hline Rhizobial & $\begin{array}{l}\text { Growth-promoting and disease-controlling } \\
\text { substances produced }\end{array}$ \\
species & \\
\hline Rhizobium sp. & $\begin{array}{l}\text { Growth hormones (auxin and cytokinin), indole acetic } \\
\text { acid (IAA), siderophores, HCN, ammonia, } \\
\text { exo-polysaccharides, and P-solubilization }\end{array}$ \\
Bradyrhizobium sp. & $\begin{array}{l}\text { IAA, HCN, ammonia, siderophores, } \\
\text { exo-polysaccharides, and P-solubilization } \\
\text { IAA, siderophores, HCN, ammonia, } \\
\text { exo-polysaccharides, and antifungal activity }\end{array}$
\end{tabular}

Modified and adapted from Ahemad and Kibret (2014).

The use of rhizobial strains also helps to produce plant resistance against diseases-causing pathogens. Interaction of rhizobial inoculants with the plant roots can result in plant resistance against some pathogenic bacteria, fungi, viruses, nematodes, etc. by a phenomenon known as ISR (Ahemad and Kibret, 2014; Gopalakrishnan et al., 2015). Gopalakrishnan et al. (2015) reported that rhizobial strains trigger the resistance of plants against pathogens by producing signals such as the jasmonate and/or ethylene pathway, lipopolysaccharides, flagella, homoserine lactones, cyclic lipopeptides, acetoin, and butanediol, leading to the induction of host plant's defense response against pathogens. Rhizosphere competence is also one of the mechanisms utilized by rhizobia as biocontrol agents comprising effective root colonization mixed with the capacity to survive and multiply along growing plant roots over a substantial period, in the existence of the native microflora (Compant et al., 2005). Given the significance of rhizosphere competence as an essential and effective biocontrol of plant diseases, understanding root-microbe communication, which can be affected by genetic and ecological determinants in spatial and time-based contexts, will also considerably contribute to the improvement in the effectiveness of rhizobia as a biocontrol agent.

\section{FUTURE INTERVENTIONS ON RHIZOBIAL INOCULANTS}

The utilization of multifunctional rhizobial inoculants appears most feasible to support crops to perform more competitively and endure when grown under stressful environments and also offers the possibility of decreasing chemical fertilizers. Therefore, rhizobial inoculants are a promising technology in mitigating the great worldwide complication of environmental pollution and also in generating premium income in the agricultural market. Although numerous trials have indicated improved growth, nodulation, and grain yield response of numerous legumes to rhizobial inoculation, there is a variation in the adoption of the technology by farmers worldwide (Peoples et al., 2009). The major constraints as far as the use of rhizobial inoculants are concerned have to do with small-scale local production and distribution of inoculants and improvement of the poor quality of inoculants. A study by Woomer et al. (1997) showed that lack of information concerning inoculant availability and use is a major constraint to adoption. Further, Ofori (2017) indicated that farmers and agricultural extension staff lack the necessary knowledge about inoculants coupled with the fact that researchers are not able to persuade farmers about the benefits of inoculation as a result of variations in crop response to rhizobial inoculation or researchers' incapability to show noticeable differences between uninoculated and inoculated treatments. Abrar and Letebo (2017) reported that most farmers are not attentive about the practice of rhizobial inoculation as biofertilizers as there is a knowledge gap that the practice is not the priority in crop production and even the rhizobial strains were also not explored.

According to Herridge (2008) and Ofori (2017), addressing these limitations would require private sector investment in training and education, especially in improving inoculant quality with special emphasis on research and development in rhizobial strain selection, inoculant production, and application methods. Vanlauwe et al. (2019) also suggested that future research consider understanding the factors that regulate the persistence of inoculated rhizobia, which may vary broadly among various rhizobial species and strains. Accordingly, priority should be given to the process of biological nitrogen fixation through more sustainable technologies that decrease the undesired effects of synthetic fertilization of crops. Besides, wider legume adoption, supported by coordinated legume improvement and breeding, and inoculation programs need to be further established and strengthened. Scientists should also work in cooperation to recognize and eradicate farmers' constraints in using the rhizobial inoculation technology, and expansion of knowledge and development of economic applications and management systems should be pursued. It is also important to advance the rhizosphere competence and survival of rhizobial inoculants and improve their environmental adaptation, which can be beneficial in producing a robust approach for usage by farmers.

In recent years, inoculant development approaches have shifted from single-strain to rhizobial consortia inoculation, which is based on a maximum chance of at best the inoculant escaping competitive exclusion, ensuring inoculant survival and function. Further investigation is, thus, essential to reveal further characteristics of rhizobia which could be reasonably valuable in realizing the maximum benefits of crop yield increment and control of plant diseases. Das et al. (2017) suggested novel rhizobial formulation technologies including polymer-based formulations, water-in-oil emulsion technology for producing liquid formulations, biofilm-based formulations, and application of nanotechnology for the manufacture of effective inoculant which can ensure enhanced stability, survival, and competence as biofertilizers and biocontrol under adverse ecological conditions. As a result, more investigation is required to produce more effective nodulating and diseasesuppressive rhizobial strains. Besides, rhizosphere engineering can be an alternative approach through which plants are genetically modified to discharge compounds that boost the association and proliferation of beneficial microorganisms. Future investigations also have to focus on the approaches 
of improving inoculant quality and information generation that is transferable from one site to another. Well-made effective extension service platforms and promotion policies on the role of inoculation in legumes and cropping system are also imperative and thus need to be further established and strengthened.

\section{CONCLUSIONS}

Rhizobia are the most widely and practically explored soil bacteria in agricultural practices due to their competence to form a symbiotic association with legume crops. Inoculation of legumes with rhizobia as a practice of agricultural production improvement has been established for more than a century. The main objective behind the inoculation of legumes with effective species of specific rhizobia is an improvement in the infection establishment, nodulation, biomass, yield component, yield, and nutrient uptake of the crops. This review elucidated that inoculation of legumes with rhizobia increases plant growth, nodulation, availability, uptake of nutrients, seed yield, and other traits of crops. Besides, this review expounded the potential use of rhizobial inoculants as

\section{REFERENCES}

Abbasi, M. K., Manzoor, M., and Tahir, M. M. (2010). Efficiency of Rhizobium inoculation and $\mathrm{P}$ fertilization in enhancing nodulation, seed yield and phosphorous use efficiency by field grown soybean under hilly region of Rawalakot Azad Jammu and Kashmir, Pakistan. J. Plant Nutr. 33, 1080-1102. doi: 10.1080/01904161003729782

Abdullahi, A. A., Howieson, J., O’Hara, G., Tepolilli, J., Vivas-Marfisi, A., and Yusuf, A. A. (2013). "History of Rhizobia inoculants use for grain legumes improvement in Nigeria-the journey so far," in $N_{2}$ Africa Project. N2013 Kampala Conference Paper.

Abrar, T., and Letebo, L. (2017). Isolation and characterization of rhizobia from rhizospher and root nodule of cowpea, elephant and lab lab plants. Int. J. Novel Res. Interdisciplinary Stud. 4, 1-7.

Agren, G. I., Wetterstedt, J. A. M., and Billberg, M. F. K. (2012). Nutrient limitation on terrestrial plant growth-modelling the interaction between nitrogen and phosphorus. New Phytol. 194, 829-836. doi: 10.1111/j.1469-8137.2012.04116.x

Ahemad, M., and Kibret, M. (2014). Mechanisms and applications of plant growth promoting rhizobacteria: current perspective. J. King Saud Univ. Sci. 26, 1-20. doi: 10.1016/j.jksus.2013.05.001

Ahiabor, B., Lamptey, S., Yeboah, S., and Bahari, V. (2014). Application of phosphorus fertilizer on soybean [Glycine $\max$ L. (Merril)] inoculated with rhizobium and its economic implication to farmers. Am. J. Exp. Agric. 4, 1420-1434. doi: 10.9734/AJEA/2014/10400

Ali, A., Choudhry, A., and Tanveer, A. (2000). Response of mungbean (Vigna radiata L.) genotypes to rhizobia culture. Pak. J. Agri. Sci. 37, 80-82. Available online at: https://www.pakjas.com.pk/papers/702.pdf

Allito, B. B., Ewusi-Mensah, N., and Logah, V. (2020). Legume-Rhizobium strain specificity enhances nutrition and nitrogen fixation in faba bean (Vicia faba L.). Agronomy 10:826. doi: 10.3390/agronomy10060826

Antoun, H., Bordeleau, L. M., and Gagnon, C. (1978). Antagonisme entre Rhizobium meliloti et Fusarium oxysporum en relation avec l'efficacité symbiotique. Can. J. Plant Sci. 58, 75-78. doi: 10.4141/cjps78-014

Ashoub, A. H., and Amara, M. T. (2010). Biocontrol activity of some bacterial genera against root-knot nematode, Meloidogyne incognita. J. Am. Sci. 6, 321-328.

Avis, T. J., Gravel, V., Antoun, H., and Tweddell, R. J. (2008). Multifaceted beneficial effects of rhizo-sphere microorganisms on a biocontrol of plant diseases, thus offering an opportunity to reduce the use of pesticides in agricultural production. As a result, several mechanisms of biocontrol and disease suppression employed by rhizobia have been identified as competition for infection sites and nutrients, activation of ISR, and production of different substances such as growth hormones, antibiotics, enzymes, siderophores, $\mathrm{HCN}$, and exopolysaccharides. In general, inoculation of legumes with rhizobia represents a practically effective, ecologically safe, and economic alternative means of realizing maximum benefits from agricultural production, the most feasible control of plant diseases, and a substitute of chemical use in agricultural productivity improvement. Therefore, studies on the exploitation of the potential of rhizobia would provide expansion of the technology for use by smallholder farmers, comprehensive knowledge on commercialization, and thus improvement and sustainability of agricultural production.

\section{AUTHOR CONTRIBUTIONS}

The author confirms being the sole contributor of this work and has approved it for publication.

plant health and productivity. Soil Biol. Biochem. 40, 1733-1740. doi: 10.1016/j.soilbio.2008.02.013

Bambara, S., and Ndakidemi, P. A. (2010). Phaseolus vulgaris response to Rhizobium inoculation, lime and molybdenum in selected low $\mathrm{pH}$ soil in Western Cape, South Africa. Afr. J. Agric. Res. 5, 1804-1811. doi: 10.5897/AJAR09.584

Bardin, S. D., Huang, H. C., Pinto, J., Amundsen, E. J., and Erickson, R. S. (2004). Biological control of Pythium damping-off of pea and sugar beet by Rhizobium leguminosarum bv. viceae. Can. J. Botany 82, 291-296. doi: 10.1139/ b04-003

Bhowmik, N. S., and Das, A. (2018). "Biofertilizers: a sustainable approach for pulse production," in Legumes for Soil Health and Sustainable Management, eds R. Meena, A. Das, G. Yadav, and R. Lal (Berlin: Springer), 445-485.

Brockwell, J., and Bottomley, P. J. (1995). Recent advances in inoculant technology and prospects for the future. Soil Biol. Biochem. 27, 683-697. doi: 10.1016/0038-0717(95)98649-9

Brockwell, J., Pilka, A., and Holliday, R. A. (1991). Soil pH is a major determinant of the numbers of naturally occurring Rhizobium meliloti in non-cultivated soils in central New South Wales. Australian. J. Exp. Agric. 31, 211-219. doi: 10.1071/EA9910211

Chandra, S., Choure, K., Dubey, R. C., and Maheshwari, D. K. (2007). Rhizosphere competent Mesorhizobium loti MP6 induces root hair curling, inhibits Sclerotinia sclerotiorum and enhances growth of Indian mustard (Brassica campestris). Brazil. J. Microbiol. 38, 124-130. doi: 10.1590/S1517-83822007000100026

Chao, W. L. (1990). Antagonistic activity of Rhizobium spp. against beneficial and plant pathogenic fungi. Lett. Appl. Microbiol. 10, 213-215. doi: 10.1111/j.1472-765X.1990.tb01336.x

Chernin, L., and Glick, B. R. (2012). "The use of ACC deaminase to increase the tolerance of plants to various phytopathogens," in Bacteria in Agrobiology: Stress Management, ed D. K. Maheshwari (Berlin: Springer-Verlag), 279-299.

Compant, S., Duffy, B., Nowak, J., Clément, C., and Barka, E. A. (2005). Use of plant growth-promoting bacteria for biocontrol of plant diseases: principles, mechanisms of action, and future prospects. Appl. Environ. Microbiol. 71, 4951-4959. doi: 10.1128/AEM.71.9.4951-4959.2005

Coutinho, H. L. C., Kay, H. E., Manfio, G. P., Naves, M. C. P., Ribeiro, J. R. A., Rumjanek, N. G., et al. (1999). Molecular evidence for shifts in polysaccharide composition associated with adaptation of soybean 
Bradyrhizobium strains to the Brazilian Cerrado soils. Environ. Microbiol. 1, 401-408. doi: 10.1046/j.1462-2920.1999.00047.x

Das, K., Prasanna, R., and Saxena, A. K. (2017). Rhizobia: a potential biocontrol agent for soilborne fungal pathogens. Folia Microbiol. 62, 425-435. doi: 10.1007/s12223-017-0513-z

Deaker, R., Roughley, R. J., and Kennedy, I. R. (2006). Legume seed inoculation technology - a review. Soil Biol. Biochem. 36, 1275-1288. doi: 10.1016/j.soilbio.2004.04.009

Denton, M. D., Coventry, D. R., Murphy, P. J., Howieson, J. G., and Bellotti, W. D. (2002). Competition between inoculant and naturalised Rhizobium leguminosarum bv. trifolii for nodulation of annual clovers in alkaline soils. Aust. J. Agric. Res. 53, 1019-1026. doi: 10.1071/AR01138

Deshwal, V. K., Pandey, P., Kang, S. C., and Maheshwari, D. K. (2003). Rhizobia as a biological control agent against soil borne plant pathogenic fungi. Indian J. Exp. Biol. 41, 1160-1164.

Dey, R., Pal, K. K., Bhatt, D. M., and Chauhan, S. M. (2004). Growth promotion and yield enhancement of peanut (Arachis hypogaea L.) by application of plant growth promoting rhizobacteria. Microbiol. Res. 159, 371-394. doi: 10.1016/j.micres.2004.08.004

Díaz-Valle, A., López-Calleja, A. C., and Alvarez-Venegas, R. (2019). Enhancement of pathogen resistance in common bean plants by inoculation with Rhizobium etli. Front. Plant Sci. 10:1317. doi: 10.3389/fpls.2019.01317

Duan, J., Muller, K. M., Charles, T. C., Vesely, S., and Glick, B. R. (2009). 1-Aminocyclopropane-1carboxylate (ACC) deaminase gene in Rhizobium from Southern Saskatchewan. Microbial. Ecol. 57, 423-436. doi: 10.1007/s00248-008-9407-6

Dubey, P., Gupta, G. P., and Dubey, R. C. (2012). Culture filtrates of plant growth promoting Bradyrhizobium sp.(Vigna) strains VR1 and VR2 inhibit growth and sclerotia germination of Macrophomina phaseolina in vitro. New York Sci J $5,1-9$.

Egamberdieva, D., and Adesemoye, A. O. (2016). "Improvement of crop protection and yield in hostile agroecological conditions with PGPR-based biofertilizer formulations," in Bioformulations: for Sustainable Agriculture, eds N. Arora, S. Mehnaz, and R. Balestrini (New Delhi: Springer), 199-211.

Ehteshamul-Haque, S., and Ghaffar, A. (1993). Use of rhizobia in the control of root rot diseases of sunflower, okra, soybean and mungbean. J. Phytopathol. 138, 157-163. doi: 10.1111/j.1439-0434.1993.tb01372.x

Elbadry, M., Taha, R. M., Eldougdoug, K. A., and Gamal-Eldin, H. (2006). Induction of systemic resistance in faba bean (Vicia faba L.) to bean yellow mosaic potyvirus (BYMV) via seed bacterization with plant growth promoting rhizobacteria. J. Plant Dis. Protect. 113, 247-251. doi: 10.1007/BF03356189

Fatima, Z., Zia, M., and Chaudhary, M. F. (2007). Interactive effect of Rhizobium strains and $\mathrm{P}$ on soybean yield, nitrogen fixation and soil fertility. Pak. J. Bot. $39,255-264$.

Fituma, T. (2015). Effect of Bradyrhizobium inoculation and phosphorus rate on nodulation, yield and yield related traits of soybean intercropped with sugarcane in Metahara Sugar Estate, Central Rift Valley of Ethiopia (M.Sc. Thesis). Haramaya University, Dire Dawa, Ethiopia.

Giller, K. E. (2001). Nitrogen Fixation in Tropical Cropping Systems, 2nd Edn. Wallingford: $\mathrm{CAB}$ International.

Gopalakrishnan, S., Sathya, A., Vijayabharathi, R., Varshney, R. K., Gowda, C. L., and Krishnamurthy, L. (2015). Plant growth promoting rhizobia: challenges and opportunities. 3 Biotech 5, 355-377. doi: 10.1007/s13205-014-0241-x

Graham, P. H., Draeger, K. J., Ferrey, M. L., Conroy, M. J., and Hammer, B. E. (1994). Acid pH tolerance in strains of Rhizobium and Bradyrhizobium, and initial studies on the basis for acid tolerance of Rhizobium tropici UMR1899. Can. J. Microbiol. 40, 198-207. doi: 10.1139/m94-033

Hallmann, J., Quadt-Hallmann, A., Mahaffee, W. F., and Kloepper, J. W. (1997). Bacterial endophytes in agricultural crops. Can. J. Microbiol. 43, 895-914. doi: $10.1139 / \mathrm{m} 97-131$

Hallmann, J., Quadt-Hallmann, A., Miller, W. G., Sikora, R. A., and Lindow, S. E. (2001). Endophytic colonization of plants by the biocontrol agent Rhizobium etli G12 in relation to Meloidogyne incognita infection. Phytopathology 91, 415-422. doi: 10.1094/PHYTO.2001.91.4.415

Hemissi, I., Mabrouk, Y., Neila, A., Bouraoui, M., Saidi, M., and Bouaziz, S. I. F. I. (2011). Effects of some Rhizobium strains on chickpea growth and biological control of Rhizoctonia solani. Afr. J. Microbiol. Res. 5, 4080-4090. doi: 10.5897/AJMR10.903
Herridge, D. (2008). "Inoculation technology for legumes," in Nitrogen-Fixing Leguminous Symbioses (Springer), 77-115.

Howieson, J. G., and Dilworth, M. J. (eds.). (2016). Working With Rhizobia. Australian Center for International Agricultural Research. ACIAR Monograph No. 173. Canberra, ACT.

Huang, H. C., and Erickson, R. S. (2007). Effect of seed treatment with Rhizobium leguminosarum on pythium damping-off, seedling height, root nodulation, root biomass, shoot biomass, and seed yield of pea and lentil. J. Phytopathol. 155, 31-37. doi: 10.1111/j.1439-0434.2006.01189.x

Ibrahim, K. A., Elsheikh, E. A. E., Naim, A. M. E. I., and Mohamed, E. A. (2011). Effect of Bradyrhizobium inoculation on yield and yield's components of soybean (Glycine max L.) grown in Sudan. Aust. J. Basic Appl. Sci. 5, 793-799.

Jesus, E. C., Leite, R. A., Bastos, R. A., Aragão, O. O. S., and Araújo, A. P. (2018). Co-inoculation of Bradyrhizobium stimulates the symbiosis efficiency of Rhizobium with common bean. Plant Soil 425, 201-215. doi: 10.1007/s11104-017-3541-1

John, N. T. (2015). Effect of rhizobium phaseoli inoculation and phosphorus application on nodulation, growth and yield components of two drybean (Phaseolus vulgaris) cultivars (MSc Mini- Dissertation). University of Limpopo, Polokwane, South Africa.

Kaur, N., Sharma, P., and Sharma, S. (2015). Co-inoculation of Mesorhizobium sp. and plant growth promoting rhizobacteria Pseudomonas sp. as bio-enhancer and bio-fertilizer in chickpea (Cicer arietinum L.). Legume Res. 38, 367-374. doi: 10.5958/0976-0571.2015.00099.5

Kebede, E. (2020a). Grain legumes production and productivity in Ethiopian smallholder agricultural system, contribution to livelihoods and the way forward. Cogent Food Agricult. 6:1722353. doi: 10.1080/23311932.2020.1722353

Kebede, E. (2020b). Grain legumes production in Ethiopia: a review of adoption, opportunities, constraints and emphases for future interventions. Turkish J. Agricult. Food Sci. Technol. 8, 977-989. doi: 10.24925/turjaf.v8i4.977-989.3254

Kebede, E., Amsalu, B., Argaw, A., and Tamiru, S. (2021). Ecophysiological and physiological characterization of cowpea nodulating native rhizobia isolated from major production areas of Ethiopia. Cogent Biol. 6:1875672. doi: $10.1080 / 23312025.2021 .1875672$

Kelemu, S., Thomas, R. J., Moreno, C. X., and Ocampo, G. I. (1995). Strains of Bradyrhizobium from tropical forage legumes inhibit Rhizoctonia solani AG-1 in vitro. Austral. Plant Pathol. 24, 168-172. doi: 10.1071/APP9950168

Khan, M. R., Mohiddin, F. A., and Ahamad, F. (2017). Inoculant rhizobia suppressed root-knot disease, and enhanced plant productivity and nutrient uptake of some field-grown food legumes. Acta Agricult. Scand. Sect. B Soil Plant Sci. 68, 166-174. doi: 10.1080/09064710.2017.1374448

Khanna, K., Jamwal, V. L., Kohli, S. K., Gandhi, S. G., Ohri, P., Bhardwaj, R., et al. (2019). Role of plant growth promoting Bacteria (PGPRs) as biocontrol agents of Meloidogyne incognita through improved plant defense of Lycopersicon esculentum. Plant Soil 436, 325-345. doi: 10.1007/s11104-019-03932-2

Koskey, G., Mburu, S. W., Awino, R., Njeru, E. M., and Maingi, J. M. (2021). Potential use of beneficial microorganisms for soil amelioration, phytopathogen biocontrol, and sustainable crop production in smallholder agroecosystems. Fron. Sustain. Food Syst. 5:606308. doi: $10.3389 /$ fsufs.2021.606308

Kumaga, F. K., and Ofori, K. (2004). Response of soybean to Bradyrhizobia inoculation and phosphorus application. Int. J. Agric. Bio 6, 324-327.

Kumar, H., Dubey, R. C., and Maheshwari, D. K. (2011). Effect of plant growth promoting rhizobia on seed germination, growth promotion and suppression of Fusarium wilt of fenugreek (Trigonella foenum-graecum L.). Crop Prot. 30, 1396-1403. doi: 10.1016/j.cropro.2011.05.001

Lindeque, M. I. (2007). Diversity of root nodule bacteria associated with Phaseolus coccineus and Phaseolus vulgaris species in South Africa (MSc Thesis). University of Pretoria, Pretoria, South Africa.

Lindström, K., Lipsanen, P., and Kaijalainen, S. (1990). Stability of markers used for identification of two Rhizobium galegae inoculant strains after five years in the field. Appl. Environ. Microbiol. 56, 444-450. doi: 10.1128/aem.56.2.444-450.1990

Mahdy, M., Hallmann, J., and Sikora, R. A. (2001). Influence of plant species on the biological control activity of the antagonistic rhizobacterium Rhizobium etli strain G12 toward the root-knot nematode, Meloidogyne incognita. Mededelingen (Rijksuniversiteit te Gent. Fakulteit van 
de Landbouwkundige en Toegepaste Biologische Wetenschappen), $66,655-662$.

Makoi, J. H., Bambara, S., and Ndakidemi, P. A. (2013). Rhizobium inoculation and the supply of Molybdenum and lime affect the uptake of macro elements in common bean (P. vulgaris L.) plants. Aust. J. Crop Sci. 7 784-793.

Martínez-Viveros, O., Jorquera, M. A., Crowley, D. E., Gajardo, G. M. L. M., and Mora, M. L. (2010). Mechanisms and practical considerations involved in plant growth promotion by rhizobacteria. J. Soil Sci. Plant Nutr. 10, 293-319. doi: $10.4067 / S 0718-95162010000100006$

Matse, D. T., Huang, C., Huang, Y., and Yen, M. (2020). Effects of coinoculation of Rhizobium with plant growth promoting rhizobacteria on the nitrogen fixation and nutrient uptake of Trifolium repens in low phosphorus soil. J. Plant Nutr. 43, 739-752. doi: 10.1080/01904167.2019.1702205

Mishra, R. P., Singh, R. K., Jaiswal, H. K., Kumar, V., and Maurya, S. (2006). Rhizobium-mediated induction of phenolics and plant growth promotion in rice (Oryza sativa L.). Curr. Microbiol. 52, 383-389. doi: 10.1007/s00284-005-0296-3

Namvar, A., Sharifi, R. S., Khandan, T., and Moghadam, M. J. (2013). Seed inoculation and inorganic nitrogen fertilization effects on some physiological and agronomical traits of chickpea (Cicer arietinum L.) in irrigated condition. J. Central European Agric. 14, 28-40. doi: 10.5513/JCEA01/14.3.1281

Ndakidemi, P. A., Dakora, F. D., Nkonya, E. M., Ringo, D., and Mansoor, H. (2006). Yield and economic benefits of common bean (Phaseolus vulgaris) and soybean (Glycine max) inoculation in northern Tanzania. Aust. J. Exp. Agric. 46, 571-577. doi: 10.1071/EA03157

Ndakidemi, P. A., Bambara, S., and Makoi, J. H. J. R. (2011). Micronutrient uptake in common bean (Phaseolus vulgaris L.) as affected by Rhizobium inoculation, and the supply of molybdenum and lime. Plant Omics J. 4, 40-52.

Noreen, R., Shafique, A., Haque, S. E., and Ali, S. A. (2016). Role of mungbean root nodule associated fluorescent Pseudomonas and rhizobia in suppressing the root rotting fungi and root knot nematodes in chickpea (Cicer arietinum L.). Pak. J. Bot. 48, 2139-2145.

Nyoki, D., and Ndakidemi, P. A. (2013). Economic benefits of Bradyrhizobium japonicum inoculation and phosphorus supplementation in cowpea (Vigna unguiculata). Am. J. Res. Commun. 1, 173-189.

Nyoki, D., and Ndakidemi, P. A. (2014). Effects of Bradyrhizobium japonicum inoculation and supplementation with phosphorus on macronutrients uptake in cowpea (Vigna unguiculata L. Walp). Am. J. Plant Sci. 5, 442-451. doi: 10.4236/ajps.2014.54058

Ofori, P. (2017). Yield response of soybean and cowpea to rock phosphate fertilizer blend and rhizobial inoculation on two benchmark soils of Northern Ghana (Doctoral dissertation). KNUST. Available online at: http://hdl.handle.net/ $123456789 / 10422$

Osdaghi, E., Shams-Bakhsh, M., Alizadeh, A., Lak, M. R., and Maleki, H. H. (2011). Induction of resistance in common bean by Rhizobium leguminosarum bv. phaseoli and decrease of common bacterial blight. Phytopathol. Mediterranea 50, 45-54.

Peoples, M. B., Brockwell, J., Herridge, D. F., Rochester, I. J., Alves, B. I. R., Urquiaga, S., et al. (2009). The contributions of nitrogen-fixing crop legumes to the productivity of agricultural systems. Symbiosis 48, 1-17. doi: $10.1007 /$ BF03179980

Ravikumar, R. (2012). Growth effects of Rhizobium inoculation in some legume plants. Int. J. Curr. Sci. 1, 1-6.

Raza, A., Zahra, N., Hafeez, M. B., Ahmad, M., Iqbal, S., Shaukat, K., et al. (2020). "Nitrogen fixation of legumes: biology and physiology," in The Plant Family Fabaceae, eds M. Hasanuzzaman, S. Araújo, and S. Gill (Singapore: Springer), 43-74.

Rechiatu, A., Nana, E. M., and Clement, A. R. (2015). Response of soybean (Glycine max L.) to rhizobia inoculation and molybdenum application in the Northern Savannah Zones of Ghana. J. Plant Sci. 3, 64-70. doi: $10.11648 /$ j.jps.20150302.14

Regar, M. K., Meena, R. H., Jat, G., and Mundra, S. L. (2017). Effect of different rhizobial strains on growth and yield of soybean [Glycine $\max (\mathrm{L}$.) Merrill]. Int. J. Curr. Microbiol. App. Sci. 6, 3653-3659. doi: 10.20546/ijcmas.2017. 611.427

Reitz, M., Rudolph, K., Schröder, I., Hoffmann-Hergarten, S., Hallmann, J., and Sikora, R. A. (2000). Lipopolysaccharides of Rhizobium etli strain G12 act in potato roots as an inducing agent of systemic resistance to infection by the cyst nematode Globodera pallida. Appl. Environ. Microbiol. 66, 3515-3518. doi: 10.1128/AEM.66.8.3515-3518.2000

Ronner, E., Franke, A. C., Vanlauwe, B., Dianda, M., Edeh, E., Ukem, B., Bala, A., vanHeerwaarden, J., and Giller, K. E. (2016). Understanding variability in soybean yield and response to P-fertilizer and rhizobium inoculants on farmers' fields in northern Nigeria. Field Crops Res. 186, 133-145. doi: $10.1016 /$ j.fcr.2015.10.023

Sahai, P., and Chandra, R. (2011). Performance of liquid and carrier-based inoculants of Mesorhizobium ciceri and PGPR (Pseudomonas diminuta) in chickpea (Cicer arietinum L.) on nodulation, yield and soil properties. J. Indian Soc. Soil Sci. 59, 263-267.

Santos, M. S., Nogueira, M. A., and Hungria, M. (2019). Microbial inoculants: reviewing the past, discussing the present and previewing an outstanding future for the use of beneficial bacteria in agriculture. AMB Express 9, 1-22. doi: 10.1186/s13568-019-0932-0

Shahid, M. Q., Saleem, M. F., Khan, H. Z., and Anjum, S. A. (2009). Performance of soybean (Glycine max L.) under different phosphorus levels and inoculation. Pakistan J. Agric. Sci. 46, 237-241.

Shamseldin, A., Abdelkhalek, A., and Sadowsky, M. J. (2017). Recent changes to the classification of symbiotic, nitrogen-fixing, legume-associating bacteria: a review. Symbiosis 71, 91-109. doi: 10.1007/s13199-016-0462-3

Shinwari, Z. K., Tanveer, F., and Iqrar, I. (2019). "Role of microbes in plant health, disease management, and abiotic stress management," in Microbiome in Plant Health and Disease, eds V. Kumar, R. Prasad, M. Kumar, and D. Choudhary (Singapore: Springer), 231-250.

Siddiqui, Z. A., Baghel, G., and Akhtar, M. S. (2007). Biocontrol of Meloidogyne javanica by Rhizobium and plant growth-promoting rhizobacteria on lentil. World J. Microbiol. Biotechnol. 23, 435-441. doi: 10.1007/s11274-006-9244-z

Sidhu, H. S. (2018). Potential of plant growth-promoting rhizobacteria in the management of nematodes: a review. J. Entomol. Zool. Stud. 6, 1536-1545.

Singh, R., and Srivastava, R. S. (1983). Effect of nitrogen nutrition and Rhizobium on multiplication and symptom expression of common bean mosaic virus in mung bean. J. Plant Dis. Protection 90, 207-212.

Singh, Z., and Singh, G. (2018). Role of Rhizobium in chickpea (Cicer arietinum) production - a review. Agric. Rev. 39, 31-39. doi: 10.18805/ag.R-1699

Singleton, P. W., Bohlool, B. B., and Nakoo, P. L. (1992). Legume response to rhizobia inoculation in the tropics: myths and realities. Myths Sci. Soils Tropics 29, 135-155. doi: 10.2136/sssaspecpub29.c8

Soenens, A., and Imperial, J. (2018). Novel, non-symbiotic isolates of Neorhizobium from a dryland agricultural soil. PeerJ 6:e4776. doi: $10.7717 /$ peerj.4776

Sprent, J. I., Ardley, J., and James, E. K. (2017). Biogeography of nodulated legumes and their nitrogen-fixing symbionts. New Phytol. 215, 40-56. doi: $10.1111 /$ nph.14474

Stagnari, F., Maggio, A., Galieni, A., and Pisante, M. (2017). Multiple benefits of legumes for agriculture sustainability: an overview. Chem. Biol. Technol. Agricult. 4, 1-13. doi: 10.1186/s40538-016-0085-1

Stephens, J. H. G., and Rask, H. M. (2000). Inoculant production and formulation. Field Crops Res. 65, 249-258. doi: 10.1016/S0378-4290(99)00090-8

Tagore, G. S., Namdeo, S. L., and Shah, S. K. (2014). Effect of microbial inoculants on nutrient uptake, yield and quality of chickpea genotypes. Int. J. Agric. Sci. Vet. Med. 2, 19-23.

Tagore, G. S., Namdeo, S. L., Sharma, S. K., and Narendra, K. (2013). Effect of Rhizobium and phosphate solubilizing bacterial inoculants on symbiotic traits, nodule leghemoglobin, and yield of chickpea genotypes. Int. J. Agron. 2013:581627. doi: 10.1155/2013/581627

Taha, A. H. Y. (1993). "Nematode interactions with root-nodule bacteria," in Nematode Interactions, ed M. W. Khan (Dordrecht: Springer), 175-202.

Tairo, E. V., and Ndakidemi, P. A. (2014). Macronutrients uptake in soybean as affected by Bradyrhizobium japonicum inoculation and phosphorus (P) supplements. Am. J. Plant Sci. 5:2014.

Tamiru, G., and Muleta, D. (2018). The effect of rhizobia isolates against black root rot disease of faba bean (Vicia faba L) caused by Fusarium solani. Open Agric. J. 12, 131-147. doi: 10.2174/1874331501812010131

Tariq, M., Khan, A., Asif, M., Khan, F., Ansari, T., Shariq, M., et al. (2020). Biological control: a sustainable and practical approach for plant disease management. Acta Agricult. Scand. Sect. B Soil Plant Sci. 70, 507-524. doi: $10.1080 / 09064710.2020 .1784262$ 
Thies, J. E., Singleton, P. W., and Bohlool, B. B. (1991). Influence of the size of indigenous rhizobial populations on establishment and symbiotic performance of introduced rhizobia on field grown legumes. Appl. Environ. Microbiol. 57, 19-28. doi: 10.1128/aem.57.1.19-28.1991

Uddin, M., Hussain, S., Khan, M. M. A., Hashmi, N., Idrees, M., Naeem, M., et al. (2014). Use of $\mathrm{N}$ and $\mathrm{P}$ biofertilizers reduces inorganic phosphorus application and increases nutrient uptake, yield and seed quality of chickpea. Turkish J. Agric. Fores 38, 47-54. doi: 10.3906/tar-1210-36

Vanlauwe, B., Hungria, M., Kanampiu, F., and Giller, K. E. (2019). The role of legumes in the sustainable intensification of African smallholder agriculture: lessons learnt and challenges for the future. Agric. Ecosyst. Environ. 284:106583. doi: 10.1016/j.agee.2019.106583

Volpiano, C. G., Lisboa, B. B., Granada, C. E., José, J., de Oliveira, A. M. R., Beneduzi, A., et al. (2019). "Rhizobia for biological control of plant diseases," in Microbiome in Plant Health and Disease, eds V. Kumar, R. Prasad, M. Kumar, and D. Choudhary (Singapore: Springer), 315-336.

Wolde-meskel, E., van Heerwaarden, J., Abdulkadir, B., Kassa, S., Aliyi, I., Degefu, T., et al. (2018). Additive yield response of chickpea (Cicer arietinum L.) to rhizobium inoculation and phosphorus fertilizer across smallholder farms in Ethiopia. Agric. Ecosyst. Environ. 261, 144-152. doi: 10.1016/j.agee.2018.01.035

Woomer, P. L., Karanja, N. K., Mekki, E. I., Mwakalobe, B., Tembo, H., Nyika, M., et al. (1997). Indigenous population of rhizobia, legume response to inoculation and farmers awareness of inoculants in East and Southern Africa. Proc. Afr. Crop Sci. Confer. 3, 297-308.

Yadav, A. N., Kour, D., Kaur, T., Devi, R., Yadav, A., Dikilitas, M., et al. (2021). Biodiversity, and biotechnological contribution of beneficial soil microbiomes for nutrient cycling, plant growth improvement and nutrient uptake. Biocatal. Agricult. Biotechnol. 33:102009. doi: 10.1016/j.bcab.2021.102009

Zahran, H. H. (1999). Rhizobium-legume symbiosis and nitrogen fixation under severe conditions and in an arid climate. Microbiol. Mol. Biol. Rev. 63, 968-989. doi: 10.1128/MMBR.63.4.968-989.1999

Ziadi, N., Bélanger, G., Cambouris, A. N., Tremblay, N., Nolin, M. C., and Claessens, A. (2007). Relationship between P and N concentrations in corn. Agronomy J. 99, 833-841. doi: 10.2134/agronj2006.0199

Conflict of Interest: The author declares that the research was conducted in the absence of any commercial or financial relationships that could be construed as a potential conflict of interest.

Publisher's Note: All claims expressed in this article are solely those of the authors and do not necessarily represent those of their affiliated organizations, or those of the publisher, the editors and the reviewers. Any product that may be evaluated in this article, or claim that may be made by its manufacturer, is not guaranteed or endorsed by the publisher.

Copyright (C) 2021 Kebede. This is an open-access article distributed under the terms of the Creative Commons Attribution License (CC BY). The use, distribution or reproduction in other forums is permitted, provided the original author(s) and the copyright owner(s) are credited and that the original publication in this journal is cited, in accordance with accepted academic practice. No use, distribution or reproduction is permitted which does not comply with these terms. 